NASA Technıcal Memorandum 86798

NASA-TM-86798

19860017181

\title{
Buckling Behavior of René 41 Tubular Panels for a Hypersonic Aircraft Wing
}

William L. Ko, John L. Shideler, and Roger A. Fields

May 1986

HERABY RAPY

$\therefore$ j

IANGLEY FESEARCH CENTER

LIRRARY, NASA

HAS:P:PTOH, VIRGINIA

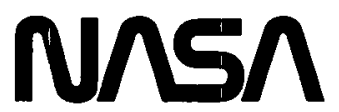

National Aeronautics and

Space Admınıstration 
31176013245320 
NASA Technical Memorandum 86798

\section{Buckling Behavior of René 41 Tubular Panels for a Hypersonic Aircraft Wing}

William L Ko

Ames Research Center, Dryden Flight Research Facilty, Edwards, Californıa John L Shideler

Langley Research Center, Hampton, Virginia

Roger A Fields

Ames Research Center, Dryden Flight Research Faclity, Edwards, California

\section{N/SA}

National Aeronautics and

Space Administration

Ames Research Center

Dryden Flight Research Facility

Edwards, Calıfornı 93523 
FOR A HYPERSONIC AIRCRAFT WING

\author{
William L. Ko* \\ NASA Ames Research Center \\ Dryden Flight Research Facility \\ Edwards, Cal1fornia
}

\section{Abstract}

The bucklıng characteristıcs of René 41 tubular panels for a hypersonic aircraft wing were investigated. The panels were repeatedly tested for buckling characteristics using a hypersonic wing test structure and a universal tension/ compression testing machine. The nondestructive buckling tests were carried out under different combined load conditions and in different temperature environments. The force/stiffness technique was used to determine the buckling loads of the panels. In spite of some data scattering resulting from large extrapolations of the datafitting curve (because of the termination of applied loads at relatively low percentages of the buckling loads), the overall test data correlate fairly well with theoretically predicted buckling interaction curves. Also, the structural efficlency of the tubular panels was found to be slightly higher than that of beaded panels.

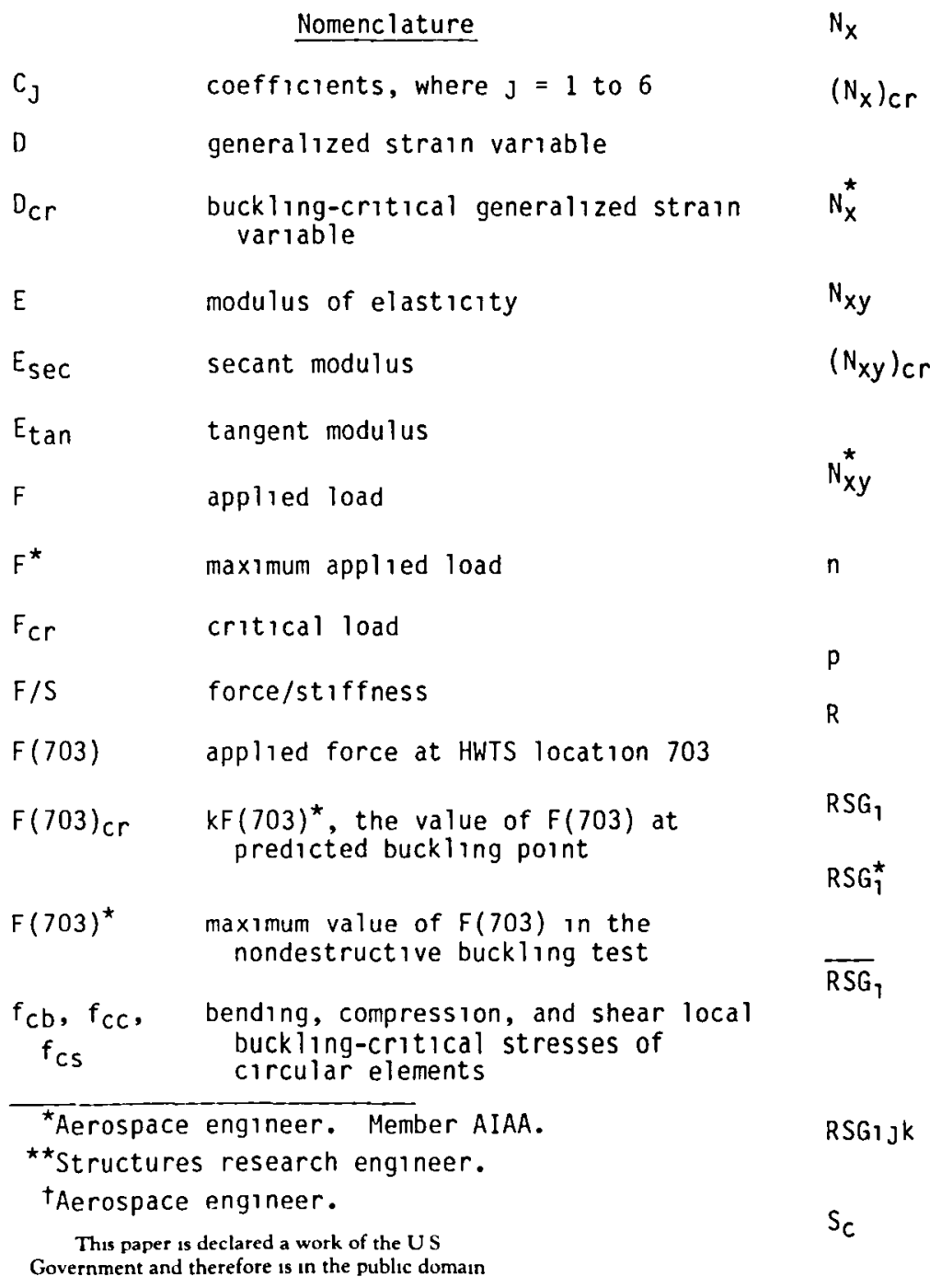

$f_{c r}$

1

$k_{S}$

k

m

$\left.N_{X}\right)_{C r}$

$N_{\mathrm{X}}^{\star}$

$\left.N_{x y}\right)_{c r}$

*

stress intensity at failure

compression yield stress

proportional-11mit stress

(threshold of inelastic stress region)

shear modulus

index

$4\left(\frac{s_{c}^{2}}{R t} \sqrt{1-v^{2}}\right)^{0.514}$

$F(703)_{C r} / F(703)^{\star}$, an extrapolation
factor

exponent in the expression of $D$

panel axial compression load, $1 \mathrm{~b} / 1 \mathrm{n}$

$k N_{x}$, the value of $N_{x}$ at buckling, $\mathrm{ib} / 1 \mathrm{n}$

the value of $\mathrm{N}_{X}$ at maximum applied load

panel shear load, $1 \mathrm{~b} / \mathrm{ln}$

$k N_{x y}$, the value of $N_{x y}$ at buckling, $1 b / 1 n$

the value of $N_{x y}$ at maximum applied load

shape factor in Ramberg-0sgood stress-strain law

lateral pressure

radius of circular arc of the panel tube cross section

rosette strain gage output

rosette strain gage output at maximum applied load $F^{*}$

rosette strain gage output with structure at uniform elevated temperature without applied mechanical load

rosette strain gage $13 k$, or its output

$2 \alpha R$, the arc length of circular arc element of the panel tube cross section 


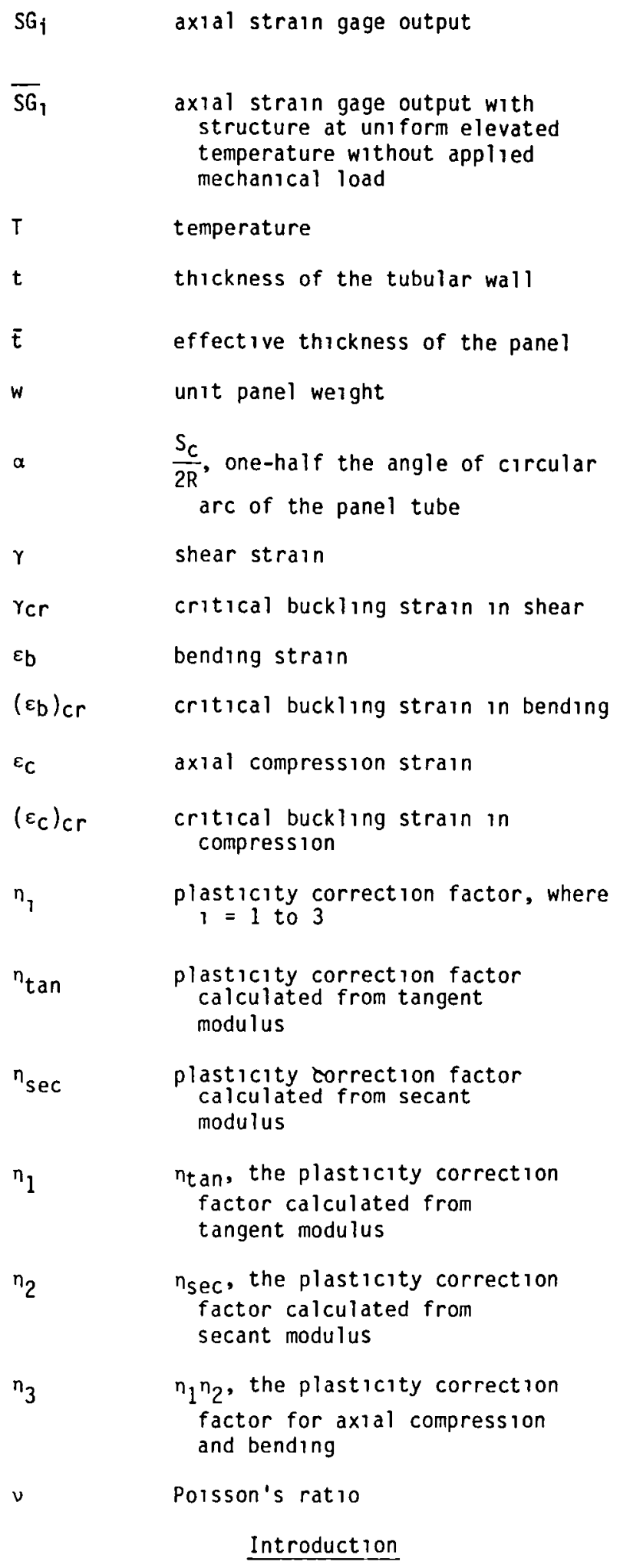

When an alrcraft reaches the hypersonic speed range, aerodynamic heating becomes significant. Hypersonic flight vehicle concepts that have been advanced include either using a thermal protection system (TPS) to prevent the vehicle from overheating or allowing an exposed vehicle surface to reach a radiation equilibrium temperature with respect to aerodynamic heating. For example, the space shuttle uses a TPS designed to limit the structural temperature to $350^{\circ} \mathrm{F}$ (a warm structure). Another concept proposed for future hypersonic a rcraft is an aerodynamically acceptable wavy heat shield made of heat-resistant metal (such as René 41) designed to limit the structural temperature to about $1350^{\circ} \mathrm{F}$ (a hot structure).

Buckling is a major concern for hot structures because of the combined effects of thermal stresses and air loads. For future hypersonic flight vehicles, advanced structural concepts that show promise of low structural unit mass and high buckling strength have been identified.2-11 Because curved shell sections exhibit high local buckling strength, most of the structural panel concepts investigated apply curved surfaces to achieve high buckling strength. Two of the hot structural panel concepts are beaded panels and circular tubular panels. Results from extensive buckling studies for René 41 beaded panels and aluminum circular tubular panels are reported in Ref. 9 and Refs. 2 to 6 , respectively. However, all the results for tubular panels were obtained from machine-controlled, room-temperature loading tests, not from tests of panels in a heated, built-up wing structure. Furthermore, only limited buckling data have been reported on René 41 noncircular tubular panels, which, for lightly loaded conditions, are more efficient than circular tubular panels, based on the computer codes analysis methods. 6

Thus, to characterize the buckling behavior of the tubular panels in a heated wing structure, five René 41 noncircular tubular panels were attached to the wing root region of the hypersonic wing test structure (HWTS, described in the Test Equipment section) for extensive nondestructive buckling tests under different combined load conditions (axial compression, bending under lateral pressure, and shear). The temperature environments used in the tests were $70^{\circ} \mathrm{F}, 550^{\circ} \mathrm{F}$, and $1000^{\circ} \mathrm{F}$. The buckling loads were estimated by using the force/stiffness ( $F / S$ ) method of plotting the test data, 10 and the results were compared with theoretically predicted buckling interaction curves.

\section{Test Panels}

Each test panel was fabricated from two sheets of Rene 41 alloy seam-welded together to form five flat regions (double sheets) and four noncircular tubular regions (flattened tubes formed by the union of two circular arcs). The dimensions of the test panel and the geometry of the noncircular tube cross section are shown in Fig. 1. Figure 2 is a photograph of one of the six tubular panels that were fabricated. The material was procured in a solution-annealed $\left(1975^{\circ} \mathrm{F}\right)$ condition. Prior to welding, the circular arcs in each sheet were incrementally brake formed, and the end closures were die formed. Doublers were spot welded to the upper and lower ends of the panel to prevent local end fallure and to reduce excessive deformations due to shear loads. After final weld assembly, the panels were aged for $1 \mathrm{hr}$ at $1650^{\circ} \mathrm{F}$ followed by $10 \mathrm{hr}$ at $1400^{\circ} \mathrm{F}$. Each panel has elght attachment points for $Z$-shaped clips to support the heat shrelds, which will be described later. A detailed description of the fabrication process is given in Refs. 3 and 6 . 


\section{Analysis}

Local Buckling

For a tubular panel with tubes of complete circular cross section, the equations for local buckling (bead crippling) of circular arc elements of the panel in compression, bending, and shear may be written as follows 2

For compression (Ref. 2, eq. 14-3),

$$
f_{C C}=0.738 n_{3} E\left(\frac{t}{R}\right)^{1.19}
$$

For bending (Ref. 2, eq. 12-33),

$$
f_{C b}=0.77 \eta_{3} E\left(\frac{t}{R}\right)^{1.15}
$$

For shear (Ref. 2, eq. 12-34),

$$
f_{c s}=\eta_{2} G K_{s}\left(\frac{t}{s_{c}}\right)^{2}
$$

where

$$
k_{S}=4\left(\frac{S_{C}^{2}}{R t} \sqrt{1-v^{2}}\right)^{0.514}
$$

Buckling equations (1) and (2) are valid for the range $20<R / t<120$, and Eq. (3) is valid for

$$
\frac{S_{C}^{2}}{R t} \sqrt{1-v^{2}}>50
$$

To apply Eq. (1) to the noncircular tubular panel, a knockdown factor of 0.86 is needed (see Ref. 6, p. 46). Equations (2) and (3) are applied directly to the flattened tubular panel without modification. The buckling equation for compression of the noncircular tubular panel is then

$$
\begin{aligned}
f_{C C} & =(0.86)(0.738) \eta_{3} E\left(\frac{t}{R}\right)^{1.19} \\
& =0.635 n_{3} E\left(\frac{t}{R}\right)^{1.19}
\end{aligned}
$$

Equations (2), (3), and (5) were used to calculate the theoretical buckling strains in bending, shear, and compression, respectively, for use in the F/S plots of the nondestructive buckling data described in the following section. The plasticity correction factors $n_{2}$ and $n_{3}$, which appear in
Eqs. (2), (3), and (5), are defined as (Ref. 2, p. 31)

$$
\begin{aligned}
& n_{1}=n_{\tan }=E_{\tan } / E \\
& n_{2}=n_{s e c}=E_{s e c} / E \\
& n_{3}=n_{1} n_{2}=n_{\tan } n_{\sec }
\end{aligned}
$$

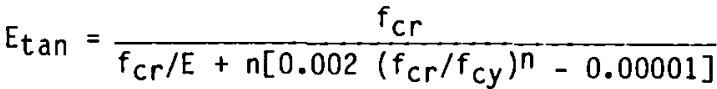

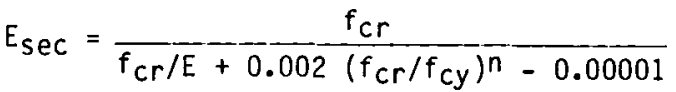

where

$$
f_{c r}>f_{p \ell}=f_{c y}(0.005)^{1 / n}
$$

and

$$
E_{\text {tan }}=E_{\text {sec }}=E \text { if } f_{c r}<f_{p \ell}
$$

The shape factor $n$ in the Ramberg-Osgood stressstrain laws for Rene 41 (Eqs. (9) to (11)) was taken as $n=25$ at $70^{\circ} \mathrm{F}, 22.2$ at $550^{\circ} \mathrm{F}$, and 18.5 at $1000^{\circ} \mathrm{F}$. Figures 3,4 , and 5 show the plots of equivalent elastic stress $f_{C r} / \eta_{1}(r=1,2,3)$ as a function of, actual stress $f_{c r}$ for the three temperatures $70^{\circ} \mathrm{F}, 550^{\circ} \mathrm{F}$, and $1000^{\circ} \mathrm{F}$, respect 1 vely. Figure 6 shows values of the modulus of elasticity $E$ and shear modulus $G$ for Rene 41 as functions of temperature.12 With the ald of Figs. 3 to 6 , the theoretical critical buckling strains in compression $\left(\varepsilon_{c}\right)_{c r}$, in bending $\left(\varepsilon_{b}\right)_{c r}$, and in shear $\gamma_{c r}$ can be calculated from Eqs. (5), (2), and (3), respectively, as

$$
\begin{aligned}
\left(\varepsilon_{c}\right)_{c r} & =\frac{f_{c c}}{n_{3} E} \\
\left(\varepsilon_{b}\right)_{c r} & =\frac{f_{c b}}{n_{3} E} \\
\gamma_{c r} & =\frac{f_{c s}}{n_{2} G}
\end{aligned}
$$

The values of $\left(\varepsilon_{c}\right)_{c r},\left(\varepsilon_{b}\right)_{c r}, Y_{c r}$ (with corresponding values of $\eta_{2}$ and $\left.\eta_{3}\right), E$, and $G$ for the different temperatures are tabulated below.

\begin{tabular}{llll}
\hline & $70^{\circ} \mathrm{F}$ & $550^{\circ} \mathrm{F}$ & $1000^{\circ} \mathrm{F}$ \\
\hline$\left(\varepsilon_{\mathrm{c}}\right)_{\mathrm{Cr}}$ & $2.330 \times 10^{-3}\left(n_{3}=1\right)$ & $2.330 \times 10^{-3}\left(n_{3}=1\right)$ & $2.330 \times 10^{-3}\left(n_{3}=1\right)$ \\
$\left(\varepsilon_{\mathrm{b}}\right)_{\mathrm{Cr}}$ & $3.412 \times 10^{-3}\left(n_{3}=0.96\right)$ & $3.412 \times 10^{-3}\left(n_{3}=0.97\right)$ & $3.412 \times 10^{-3}\left(n_{3}=0.99\right)$ \\
$Y_{\mathrm{Cr}}$ & $2.208 \times 10^{-3}\left(n_{2}=1\right)$ & $2.208 \times 10^{-3}\left(n_{2}=1\right)$ & $2.208 \times 10^{-3}\left(n_{2}=1\right)$ \\
$\mathrm{E}\left(1 \mathrm{~b} / 1 \mathrm{n}^{2}\right)$ & $31.6 \times 10^{2}$ & $29.1 \times 10^{6}$ & $26.5 \times 10^{6}$ \\
$\mathrm{G}\left(1 \mathrm{~b} / 1 \mathrm{n}^{2}\right)$ & $12.1 \times 10^{6}$ & $11.2 \times 10^{6}$ & $10.2 \times 10^{6}$ \\
\hline
\end{tabular}


Notice that only the bending buckling strains are in the plastic range.

\section{Force/Stiffness Method}

The purpose of conducting nondestructive buckling tests instead of destructive buckling tests was to avoid the cost assocrated with destructive tests of a large number of panels. In destructive buckling tests, only one buckling data point for a certain load condition can be generated from each test panel. However, by using the $F / S$ method to predict the buckling strength, a wide range of buckling data points can be generated from the same set of test panels. The F/S method described in this paper was advanced by Jones and Greenell for the prediction of buckling strength of complex structural components having buckling behavior that is quite complex (for example, local buckling) or nonlinear.

Although local instability is usually the critical fallure mode for the tubular panels, local and panel-general instability may occur at similar loading levels when lateral pressure is low and shear is high (see Results section). If the panel-general instability were to occur first, local instability would probably also occur. Consequently, the $\mathrm{F} / \mathrm{S}$ method used to identify buckling strength was one that predicts local buckling fallure. The method uses a plot of force $F$ against stiffness $F / D$, where $F$ can be any particular load of the applied load set and D is a generalized strain variable that accounts for axial compression, bending, and shear components. The generalized strain variable $D$ is given by

$$
D=\frac{\varepsilon_{c}}{\left(\varepsilon_{c}\right)_{c r}}+\frac{\varepsilon_{b}}{\left(\varepsilon_{b}\right)_{c r}}+\left(\frac{\gamma}{\gamma_{c r}}\right)^{m}
$$

and the critical local buckling condition occurs when

$$
\mathrm{D}=\mathrm{D}_{\mathrm{Cr}}=1
$$

and

$$
\frac{F}{D}=\frac{F_{C r}}{D_{C r}}=F_{C r}
$$

The strains $\varepsilon_{C}, \varepsilon_{b}$, and $\gamma$ are measured with strain gages, and the critical strains $\left(\varepsilon_{c}\right)_{c r},\left(\varepsilon_{b}\right)_{c r}$, and $\gamma_{c r}$ (tabulated previously) are calculated from Eqs. (12), (13), and (14), respectively. The exponent $m$ in Eq. (15) was empirically determined to be 2 for most types of panels, including the complete circular tubular panels. 5 For the $F / S$ analysis described here, the value $m=2$ was used.

Equations (15) and (16) represent a critical strain interaction surface that is the basis for the limit strain lines used in the $F / S$ plots. Figure 7 graphically illustrates the $F / S$ method, which requires extrapolation of the curve fitting the test data points. The buckling fallure load is determined from the intersection of the extrapolated curve and the $11 \mathrm{mit}$ strain line. The accuracy of buckling fallure load prediction using the $F / S$ method depends on the following factors. location of strain gages (they must measure strain that is sensitive to the impending buckling mode shape), distance of extrapolation (that is, how far the test data stopping point falls from the limit strain line), how well the curve fits the data, and the accuracy with which the limit strain line itself is determined (for example, critical strains determined empirically for a specific configuration may be more accurate than critical strains determined analytically from general equations).

Extrapolation of the $F / S$ data-fitting curve to its intersection with the limit strain line is accomplished through least squares fitting of the test data by using the following third-order equation

$$
\frac{F}{D}=\frac{1+C_{1} F+C_{2} F^{2}}{C_{3}+C_{4} F+C_{5} F^{2}+C_{6} F^{3}}
$$

The critical value of $F$ (the intersection point $\left.F_{(r)}\right)$ is determined by setting $D=1$ in Eq. (17). In this $\mathrm{F} / \mathrm{S}$ analysis, $\mathrm{D}$ is expressed as follows

For room temperature, .

$$
D=\frac{S G_{1}+S G_{2}}{2\left(\varepsilon_{c}\right)_{c r}}+\frac{\left|S G_{1}-S G_{2}\right|}{2\left(\varepsilon_{b}\right)_{c r}}+\left[\frac{2\left|R S G_{2}-R S G_{3}\right|}{\sqrt{3} \gamma_{c r}}\right]^{2}
$$

For elevated temperatures,

$$
\begin{aligned}
& D= \frac{\left(S G_{1}-\overline{S G}_{1}\right)+\left(S G_{2}-\overline{S G}_{2}\right)}{2\left(\varepsilon_{c}\right)_{C r}} \\
&+\frac{\left|\left(S G_{1}-\overline{S G}_{1}\right)-\left(S G_{2}-\overline{S G}_{2}\right)\right|}{2\left(\varepsilon_{b}\right)_{C r}} \\
&+\left[2 \mid\left(R G_{2}-\overline{R S G_{2}}\right)-\left(R S G_{3}-\overline{\left.R S G_{3}\right)}\right]^{2}\right. \\
& \sqrt{3} \gamma_{C r}
\end{aligned}
$$

The values $S G_{1}$ and $S G_{2}$ are the outputs of the axial strain gages placed, respectively, at the lower and upper outermost fibers of the tube at the panel center region and $R S_{2}$ and $R S G_{3}$ are the outputs of the rosette strain gage legs oblique to the tube axis. Finally, the overbar indicates the initial nonzero strain gage readings at elevated temperatures when no mechanical loads were applied (panels were soaked at uniform temperature to determine these initial strains).

Panel Buckling Loads

After the critical load $F_{C r}$ is determined using the $\mathrm{F} / \mathrm{S}$ method, the associated critical panel axial compression load $\left(N_{X}\right)_{C r}$ and critical panel shear load $\left(N_{x y}\right)_{c r}$ must be determined. If $N_{x}^{\star}$ and $N_{x y}^{*}$ are the panel axial and shear loads, respectively, associated with the maximum applied 
load $F^{\star}$ (see $F_{1 g}, 7$ ) and if $\left(R S G_{1}^{*}-\overline{R S G}_{1}\right.$ ), $\left(R S G_{2}^{*}-\overline{R S G}_{2}\right)$, and $\left(R S G_{3}^{*}-\overline{R S G}_{3}\right)$ are the readings of the three legs of the rosette strain gage

when $F=F^{*},\left(\left(R S G_{1}^{*}-\overline{R S G}_{1}\right)\right.$ being in the axial direction), then $N_{x}^{\star}$ and $N_{x y}^{*}$ can be calculated as

$$
\begin{aligned}
N_{x}^{\star} & =E \bar{t}\left(R S G_{1}^{\star}-\overline{R S G}_{1}\right) \\
N_{x y}^{\star} & =\frac{2}{\sqrt{3}} G E(2 t)\left|\left(R S G_{2}^{\star}-\overline{R S G}_{2}\right)-\left(R S G_{3}^{\star}-\overline{R S G}_{3}\right)\right|
\end{aligned}
$$

where $\bar{t}$ is the effective thickness of the panel and $\operatorname{RCG}_{1}^{\star}(1=1,2,3)$ are the rosette strain gage readings at $F=F^{\star}$.

If the extrapolation factor $k$ (see Fig. 7) is defined as

$$
k \equiv \frac{F_{C r}}{F^{\star}}
$$

then $\left(N_{x}\right)_{C r}$ and $\left(N_{x y}\right)_{C r}$ can be estrmated as

$$
\begin{gathered}
\left(N_{x}\right)_{c r}=k N_{x}^{*} \\
\left(N_{x y}\right)_{c r}=k N_{x y}^{*}
\end{gathered}
$$

The values of $\left(N_{x}\right)_{C r}$ and $\left(N_{x y}\right)_{C r}$ thus obtained are used in constructing the bucking interaction plots.

\section{Test Equipment}

Combined Loads

Hypersonic Wing Test Structure. The hypersonic wing test structure (HWTS, $85 \mathrm{ft}^{2}$ in area) shown in Fig. 8 is a portion of the wing of a proposed hypersonic research airplane (HRA). shown in Fig. 9. The HRA is to be built for cruising at Mach 8 with $2.5 \mathrm{~g}$ pullup capability (Ref. 13 discusses the HRA in great detail). The HWTS was constructed based on the knowledge gained from the hot structural concepts investigations in the hypersonic cruise vehicle research program.1,14 The HWTS has been tested extensively to evaluate the structural concept itself, the final structural design, the flight loads instrumentation, high-temperature calibration methods, and temperature simulation techniques. The beaded skin panels and corrugated spars and ribs are made of René 41 nickel alloy. The heat shrelds are also made of Rene 41 alloy except for those along the leading edge, which are made of TD $N_{1}-20 \mathrm{Cr}$. The heat shields are single-sheet panels, which are slightly corrugated in the chordwise direction and capable of operating with surface temperature in excess of $1800^{\circ} \mathrm{F}$. The heat shields are separated from the beaded skin panels by Z-shaped support clips to minimize heat conduction from the heat shields to the substructure. The HWTS is mounted inverted to the support structure through a transition section ( $F 1 g .8)$, so the compressive surface of the actual vehicle would be the lower surface of the HWTS. The transition section is included to provide a buffer between the support structure and the test portion of the wing. The lower wing root zone is the most critically compression-loaded area, and the five beaded panels there can be replaced with different types of panels for testing structural efficiencies. The five tubular panels were installed in this lower wing root area for the nondestructive buckling tests. Figure 10 shows the HWTS with the heat shrelds removed to reveal the substructure and the Z-shaped clips that support the heat shrelds.

Mechanical Loading Systems. Figure 11 shows the Tocations of the five test tubular panels and the applied mechanical load distribution on the HWTS. Twenty channels of closed-loop electrohydraulic equipment were used to apply mechanical loads to the test structure at different load points, as shown in Fig. 11. Ten hydraulic jacks were used to apply vertical loads (simulating $11 \mathrm{ft}$ load) to the HWTS to induce compression loads to the test panels, eight of these jacks applied loads through two-point whiffletrees. Horizontal loads (simulating drag and thermal load from fore and aft wing structure) were applied by the remainıng 10 hydraulic jacks at single load points on the fore and aft edges of the HWTS to induce shear loads to the test panels. The pressure loads (which induced bending loads) normal to the upper surfaces of the test panels were generated through the stainless steel pressure pans positioned over the test panels.

Heating System. For the HWTS elevatedtemperature tests (s imulating aerodynamic heating), a specially constructed heating system was used (Frg. 12). The system was designed to heat the entire upper and lower surfaces of the HWTS to temperatures corresponding to a Mach 8 flight profile. Infrared quartz lamps mounted on polished aluminum reflectors (F1g. 12) were used to provide the radiant heat flux for the simulation of aerodynamic heating. The reflectors were water cooled to enable them to withstand the high temperatures achieved during the heating tests. Both the lower and the upper heating systems were slightly contoured to match the surface shape of the HWTS and were mounted on rollers and tracks (see Fig. 12) so they could be easily removed for access to the HWTS and then precisely repositioned. The heating systems were positioned with the reflector surfaces approximately $6 \mathrm{in}$. from the heat shrelds of the HWTS. Because the test structure has mechanical load attachment points on the lower surface, gaps in the lower heater were provided along the spar caps to enable connections with the hydraulic vertical loading system (Fig. 13), these gaps between load points were filled by a double row of quartz lamps mounted on separate, long, narrow, water-cooled 
aluminum reflectors (strip heaters) installed parallel to the spar caps. Heating rates were controlled through thermocouples attached to the test structure exterior surfaces. During the heating tests, insulation curtains (see Fig. 12) could be draped around the HWTS and the heating systems to reduce radiation and convection heat losses. The plumbing for the reflector cooling water included a pressure gauge for each feed line to ascertain cooling provisions.

\section{Compression 0nly}

For gathering additional room-temperature $\left(70^{\circ} \mathrm{F}\right)$ buckling data in pure compression, a universal tension/compression testing machine was used in the individual panel compression buckling tests. Figure 13 shows the test machine with the test panel mounted. The surfaces of the upper and lower platens (which come into direct contact with the panel edges) were machined flat to ensure pure compression loading and eliminate possible bending effect due to misaligned platen surfaces. The lower platen was rested on a spherical seat and provided proper alignment with the test panel.

End supports mounted on the panel provided surfaces for load transfer and served as reinforcement to eliminate warping of the panel ends. The surfaces of both end supports were milled parallel to each other and perpendicular to the panel tube axes to provide pure compression load transfer.

The panel vertical edges were bolted to the $Z$-section stiffeners to approximate the edge stiffness conditions of the panel if it were mounted on the wing. The interfaces between the panel and the $Z$ stiffeners were lubricated. The bolt holes on the $Z$ stiffeners were oval in shape so the bolts could move when the panel deformed. A total of 11 displacement transducers (DT) were used to measure the out-of-plane deformations of the test panel at 11 locations (Fig. 13).

\section{Strain Gage Instrumentation}

The strain gage locations on the surfaces of the five test panels are shown in Fig. 14, looking downward onto the top of the test panels. The strain gages with () symbols were located on the upper surfaces of the panels, the rosette strain gages with [ ] symbols were used for the elevated-temperature tests. The strain gages on the upper and lower surfaces of the pane? tubes are axial strain gages of two types forl type (circular symbol) and capacitance type (square symbol). Two of these strain gages, one of each type, were mounted end to end at each location shown in Fig. 14. Of the axial strain gages, only the capacitance strain gages were capable of operating at temperatures above $550^{\circ} \mathrm{F}$. The strain gages on the surface of the panel flat area were of the delta-rosette forl type (indicated by triangles in Fig. 14). The delta-rosette strain gages were used to make measurements at three angular orientations, spaced $120^{\circ}$ apart, starting in the direction parallel to the wing spars and rotating clockwise (when looking down on the test panels and inboard). The accuracy of the data acquisition system for strain gage measurements was \pm 4.88 microstrain, which represents 0.3 percent of the strain gage calibrated output. This provided accurate recorded data. Figure 15 shows the fully instrumented test panels attached to the HWTS lower wing root test area with panel 3 removed to show the pressure pan interior.

\section{Tests}

Combined Load Conditions

To generate a wide range of buckling data for buckling interaction plots using the $F / S$ method, a series of nondestructive buckling tests was conducted under various combined load conditions at three temperature levels $\left(70^{\circ} \mathrm{F}, 550^{\circ} \mathrm{F}\right.$, and $\left.1000^{\circ} \mathrm{F}\right)$. Table 1 shows the maximum loads applied at the load points for different load conditions. The pressure load was always maintained at the constant level of $0.751 \mathrm{~b} / \mathrm{ln}^{2}$ or at zero. For load conditions $4.1,7.1$, and 8.1 , which do not have horizontal loads, the test panels were under very little shear load. Before the series of tests at room temperature $\left(70^{\circ} \mathrm{F}\right)$, a pressure check was conducted to ensure that a constant pressure level could be maintained during the tests. For the elevated-temperature tests, a heating check was conducted before the actual buckling test to ensure that constant temperature levels could be maintained over one test period. Table 2 shows test identification numbers and corresponding load conditions.

Compression-0nly Tests

Both panels 1 and 3 were used for single-panel room-temperature $\left(70^{\circ} \mathrm{F}\right)$ compression tests up to buckling fallure. During the tests, the outputs from the load cell, strain gage channels, and DT channels were fed into the data acquisition system so that $F / S$ plots could be generated. The buckling loads obtained from the $F / S$ plots could then be compared with the actual buckling loads.

\section{Data Reductions}

In applying the $F / S$ method described previously, a typical vertical load (lift force), $F(703)$ (located at load point 703 , associated with jack number 3 , Fig. 11) was chosen for $F$ in Eq. (16) (or Fig. 7) in the F/S calculations for all the test panels. The force $F(703)$ was arbitrarily selected as a representative measurement of all applied loads since all loads were directly proportional to each other and were applied simultaneously. For $F=F(703)$, Eq. (22) becomes

$$
k=\frac{F_{c r}}{F^{*}}=\frac{F(703) c r}{F(703)^{\star}}
$$

where $F(703)_{C r}$ is the value of $F(703)$ at the predicted buckling point and $F(703)^{\star}$ is the maximum value of $F(703)$ in the nondestructive buckling test. The critical values of the panel loads $\left(N_{x}\right)_{C r}$ and $\left(N_{x y}\right)_{c r}$ may be calculated by using Eqs. (20), (21), (23), and (24). For example, for panel 1 at $70^{\circ} \mathrm{F}$ with the rosette strain gage 
combination RSG933, RSG934, and RSG935 (Fig. 14), Eqs. (20) and (21) may be written as

$$
\begin{aligned}
N_{x}^{*} & =E \bar{t}\left(R S G 933^{\star}-0\right) \\
N_{x y}^{*} & =\frac{2}{\sqrt{3}} G(2 t) \mid\left\langle\left(R S G 934^{*}-0\right)-\left(R S G 935^{*}-0\right)\right|
\end{aligned}
$$

and $\left(N_{x}\right)_{c r}$ and $\left(N_{x y}\right)_{c r}$ can be calculated from (see Eqs. (23) and (24))

$$
\begin{aligned}
& \left(N_{x}\right)_{c r}=k N_{x}^{\star}=\frac{F(703)_{c r}}{F(703)^{\star}}-N_{x}^{\star} \\
& \left(N_{x y}\right)_{c r}=k N_{x y}^{\star}=\frac{F(703)_{c r}}{F(703)^{\star}} \cdot N_{x y}^{\star}
\end{aligned}
$$

\section{Results}

Figures 16 and 17 , respectively, show the $F / S$ plots for two typical test cases $4.4 .6(p \neq 0)$ and 4.3.4 $(p=0)$. The solid curves shown in the figures were drawn by least squares fittings of the test data points. The least-squares-fit curves based on Eq. (17) tend to bend upward gradually far outside the range of the data points. For some test cases, or for certain strain gage combinations in the same test case, the least-squares-fit curves start to bend upward immediately after the last data points and intersect the limit strain lines at points that give rather high values of the buckling loads. For such cases, the extrapolations of the test data curves were accomplished by observation (or visual fittings). When there is lateral pressure $(p \neq 0)$, the $F / S$ curves are usually convex upward (Fig. 16). However, when there is no lateral pressure $(p=0)$, the $F / S$ curves are usually strongly convex downward, except for the lowload region, giving quite accurate buckling load predictions (Fig. 17). The F/S plots for the rest of the test cases are similar and therefore are not shown.

Figure 18 shows the F/S plots for panel 3 under the room-temperature $\left(70^{\circ} \mathrm{F}\right)$ single-panel compression tests. Note that the actual buckling points fell in the vicinity of the limit strain lines. This indicates that the $F / S$ method could give relatively accurate predictions of buckling loads.

In most of the $F / S$ plots, the extrapolation factor $k$ was in the approximate range of 2 to 3 .

Figures 19 to 23 show the buckling interaction plots for different temperature environments, with or without pressure. In the figures, theoretical buckling interaction curves (solid curves for panel instability, dashed curves for local buckling) are shown for comparison. These theoretical buckling interaction curves were generated through temperature and material modulus corrections of the results given in Ref. 6 (table 1 (modified analysis), p. 48) which were calculated by using equations given in Ref. 2 . The maximum applied load was $11 \mathrm{~m}$ ted to the values shown in Figs. 19 to 23 to prevent spar cap fallure in the HWTS itself. Thus, large $F / S$ data curve extrapolations were necessary. For high-compression loadings ( $F 1 g .20)$, the maximum applied load levels were not high enough to give more accurate buckling data through the $F / S$ data extrapolations. Nevertheless, the correlations between the test data and the predictions are fairly good in spite of data scatter due to the large extrapolations of the data-fitting curve for some test cases (for example, near the $N_{x}$ axis for $T=70^{\circ} \mathrm{F}$, $\left.p=0.75 \mathrm{lb} / 1 \mathrm{n}^{2}, \mathrm{~F} 1 \mathrm{~g} .20\right)$. Most of the data points, including the actual buckling points obtained from the single-panel compression tests (Fig. 19), fall outside the predicted interaction curves (surfaces), indicating that the theory is conservative. In all other cases, the theoretical curves fall within the scatter of the experimental data. Therefore, the experimental buckling data verify the theory for the applied test conditions. Notice that the existence of lateral pressure decreases the compressional buckling load $\left(N_{X}\right)_{c r}$ considerably but decreases the shear buckling load $\left(N_{x y}\right)_{C r}$ only slightly. Also, the buckling interaction curve shrinks as the temperature is increased because of decreases in $E$ and $G$. Finally, the buckling strength per unit panel werght, $\left(N_{x}\right)_{C r} / w\left(w=0.0161 \mathrm{lb} / 1 \mathrm{n}^{2}\right)$, for panels 1 and 3 were $\left(N_{X}\right)_{c r} / w=1.5068 \times 10^{5} \mathrm{in}$ and $\left(N_{X}\right)_{C r} / w=1.3280 \times 10^{5} \mathrm{in}$, respectively. These values are slightly higher than $\left(N_{x}\right)_{c r} / w=1.1507 \times 10^{5}$ in $\left(w=0.0146 \mathrm{lb} / \mathrm{ln}^{2}\right)$ for the beaded panels reported in Ref. 9 .

\section{Conclusions}

Five Rene 41 tubular panels were simultaneously and repeatedly tested for buckling characteristics using the hypersonic wing test

structure. Nondestructive buckling tests were carried out under different combined load conditions and in different temperature environments. The force/stiffness technique was used to determine buckling loads for a wide range of load conditions without falling the test panels. In spite of some data scattering due to large extrapolations of the data-fitting curve, the overall test data correlate fairly well with theoretically predicted buckling interaction curves. The existence of lateral pressure decreased the compressional buckling load $\left(\mathrm{N}_{\mathrm{X}}\right)_{\mathrm{cr}}$ considerably. However, the effect of lateral pressure on the reduction of the shear buckling load $\left(N_{x y}\right)_{c r}$ was quite small. Also, increasing the temperature was found to decrease both $\left(\mathrm{N}_{X}\right)_{c r}$ and $\left(\mathrm{N}_{x y}\right)_{\mathrm{cr}}$ because of reduc$t$ ions in the values of $E$ and $G$ at elevated temperatures. The fact that almost all the test data for nearly pure compression ( $N_{x y}$ small) at room temperature $\left(70^{\circ} \mathrm{F}\right)$ fell outside the predicted buckling interaction curves indicates that the theory used to design and predict the buckling of panels is conservative for that condition. Otherwise, the test data verify the theory for all other test conditions. Finally, the tubular panels were found to be slightly more structurally efficient than beaded panels. 
References

lPlank, P.P., Sakata, I.F., Davis, G.W., and Richie, C.C.. "Hypersonic Cruise Vehicle Wing Structure Evaluation," NASA CR-1568, 1970.

2Greene, Bruce E., "Advanced Beaded and Tubular Structural Panels, Volume 1, Design and Analysis," NASA CR-132460, 1974.

3Musgrove, Max D., and Northrup, Russell F. "Advanced Beaded and Tubular Structural Panels, Volume 2, Fabrication," NASA CR-132482, 1974.

${ }^{4}$ Hedges, Philip C., and Greene, Bruce E.,

"Advanced Beaded and Tubular Structural Panels, Volume 3, Testing," NASA CR-132515, 1974.

5Musgrove, Max D., and Greene, Bruce E., "Advanced Beaded and Tubular Structural Panels," NASA CR-2514, 1975.

6 Greene, Bruce E., and Northrup, Russell F., "Design and Fabrication of René 41 Advanced Structural Panels," NASA CR-132646, 1975.

7Musgrove, Max D., Greene, Bruce E., Shideler, John L., and Bohon, Herman L., "Advanced Beaded and Tubular Structural Panels," J. Arrcraft, vol. II, no. 2, pp. 68-75, Feb. 1974.
${ }^{8}$ Shideler, John L., Bohon, Herman L., and Greene, Bruce E., "Evaluation of Bead-Stiffened Metal Panels," AIAA Paper 75-815, AIAA/ASME/SAE 16th Structures, Structural Dymanics, and Materials Conference, Denver, Colorado, May 27-29, 1975.

${ }^{9}$ Siegel, William H., "Experimental and Finite Element Investigation of the Buckling Characteristics of a Beaded Skin Panel for a Hypersonic A r rcraft," NASA CR-144863, 1978.

10Shideler, John L., Fields, Roger A., and Reardon, Lawrence F., "Tests of Beaded and Tubular Structural Panels," NASA CP-2065, pp. 539-576, 1978.

11 Jones, Robert E., and Greene, Bruce E., "The Force/Stiffness Technique for Nondestructive Buckling Testing," AIAA Paper 74-351, AIAA/ASME/

SAE 15th Structures, Structural Dynamics, and

Materials Conference, Las Vegas, Nevada, Apr. 17-19, 1974.

12"Military Standardization Handbook - Metallic Materials and Elements for Aerospace Vehicle Structures, 5B," MIL-HDBK-5, Aug. 1973.

13F jelds, Roger A., Reardon, Lawrence $F_{.}$, and Siegel, William H., "Loading Tests of a Wing Structure for a Hypersonic Aircraft," NASA TP-1596, 1980.

14Plank, P.P., and Penning, F.A., "Hypersonic Wing Test Structure Design, Analysis, and Fabrication," NASA CR-127490, 1973.

Table 1 Maximum loads applied at load points for different load combinations

(a) $\mathrm{T}=70^{\circ} \mathrm{F}$

\begin{tabular}{|c|c|c|c|c|c|c|c|c|c|}
\hline \multirow{3}{*}{$\begin{array}{c}\text { Jack } \\
\text { number }\end{array}$} & \multirow{3}{*}{$\begin{array}{l}\text { Load cell } \\
\text { size, } 1 b\end{array}$} & \multirow{3}{*}{$\begin{array}{c}\text { Jack } \\
\text { position }\end{array}$} & \multicolumn{7}{|c|}{ Load condition identification numbera } \\
\hline & & & $3.1^{b}$ & $3.6 \mathrm{C}$ & $3.8 \mathrm{C}$ & $4.1 \mathrm{C}$ & $4.2^{\mathrm{C}}$ & $4.3 \mathrm{C}$ & $4.4 C$ \\
\hline & & & & \multicolumn{6}{|c|}{ Maximum load,d lb } \\
\hline 1 & $5 \times 10^{3}$ & Vertical & 1680 & 2521 & 4,201 & 3500 & 2800 & 1200 & -4000 \\
\hline 2 & 10 & Vertical & 869 & 1304 & 2,173 & 6000 & 2800 & 2000 & 2400 \\
\hline 3 & 10 & Vertical & 624 & 935 & 1,559 & 6000 & 2800 & 2000 & 2400 \\
\hline 4 & 5 & Vertical & 863 & 1294 & 2,157 & 3500 & 2800 & -2800 & -4000 \\
\hline 5 & 5 & Horizontal & 0 & 1650 & 2,750 & 0 & -5000 & -5000 & -5000 \\
\hline 6 & 10 & Horizontal & 0 & 4260 & 7,100 & 0 & -6500 & -6500 & -6500 \\
\hline 7 & 10 & Horizontal & 0 & -4030 & $-6,716$ & 0 & 6500 & 6500 & 6500 \\
\hline 8 & 10 & Horizontal & 0 & -1232 & $-2,054$ & 0 & 6500 & 6500 & 6500 \\
\hline 9 & 10 & Horizontal & 0 & -3840 & $-6,350$ & 0 & 6000 & 6000 & 6000 \\
\hline 10 & 10 & Horizontal & 0 & 737 & 1,229 & 0 & 6000 & 6000 & 6000 \\
\hline 11 & 10 & Vertical & 2265 & 3398 & 5,663 & 3000 & 800 & -800 & -4000 \\
\hline 12 & 5 & Vertical & -95 & -143 & -238 & 1800 & 1400 & 1200 & 1200 \\
\hline 13 & 20 & Horizontal & 0 & -6692 & $-11,154$ & 0 & 6500 & 6500 & 6500 \\
\hline 14 & 10 & Horizontal & 0 & -3945 & $-6,575$ & 0 & 6500 & 6500 & 6500 \\
\hline 15 & 10 & Horizontal & 0 & -1740 & $-2,900$ & 0 & -6500 & -6500 & -6500 \\
\hline 16 & 10 & Horizontal & 0 & 2400 & 4,000 & 0 & -6500 & -6500 & -6500 \\
\hline 17 & 5 & Vertical & 1267 & 1901 & 3,168 & 3500 & 2800 & 2800 & 4000 \\
\hline 18 & 5 & Vertical & -1846 & -2770 & $-4,616$ & 3500 & 4800 & 4800 & 4000 \\
\hline 19 & 5 & Vertical & 1760 & 2640 & 4,400 & 2800 & 2800 & 2800 & 4000 \\
\hline 20 & 5 & Vertical & 542 & 814 & 1,356 & 1800 & 1400 & 1200 & 1200 \\
\hline
\end{tabular}

aLoad number 0.75 was a $0.75-16 / 1 n^{2}$ pressure test.

bpressure load maintained at 0 .

cTests conducted at pressure loads of 0 and $0.75 \mathrm{lb} / 1 \mathrm{n}^{2}$.

dpositive values indicate tension, negative values indicate compression. 
Table 1 Continued.

(b) $\mathrm{T}=550^{\circ} \mathrm{F}$

\begin{tabular}{|c|c|c|c|c|c|c|c|c|}
\hline \multirow{3}{*}{$\begin{array}{c}\text { Jack } \\
\text { number }\end{array}$} & \multirow{3}{*}{$\begin{array}{l}\text { Load cell } \\
\text { size, ib }\end{array}$} & \multirow{3}{*}{$\begin{array}{c}\text { Jack } \\
\text { position }\end{array}$} & \multicolumn{6}{|c|}{ Load condition identification number $a, b$} \\
\hline & & & 6.6 & 6.8 & 7.1 & 7.2 & 7.3 & 7.4 \\
\hline & & & \multicolumn{6}{|c|}{ Maximum load,c lb } \\
\hline 1 & $5 \times 10^{3}$ & Vertical & 2521 & 4,201 & 3500 & 2800 & 1200 & -4000 \\
\hline 2 & 10 & Vertical & 1304 & 2,173 & 6000 & 2800 & 2000 & 2400 \\
\hline 3 & 10 & Vertical & 935 & 1,559 & 6000 & 2800 & 2000 & 2400 \\
\hline 4 & 5 & Vertical & 1294 & 2,157 & 3500 & 2800 & -2800 & -4000 \\
\hline 5 & 5 & Horizontal & 1650 & 2,750 & 0 & -5000 & -5000 & -5000 \\
\hline 6 & 10 & Horizontal & 4260 & 7,100 & 0 & -6500 & -6500 & -6500 \\
\hline 7 & 10 & Horizontal & -4030 & $-6,716$ & 0 & 6500 & 6500 & 6500 \\
\hline 8 & 10 & Horizontal & -1232 & $-2,054$ & 0 & 6500 & 6500 & 6500 \\
\hline 9 & 10 & Horizontal & -3840 & $-6,350$ & 0 & 6000 & 6000 & 6000 \\
\hline 10 & 10 & Horizontal & 737 & 1,229 & 0 & 6000 & 6000 & 6000 \\
\hline 11 & 10 & Vertical & 3398 & 5,663 & 3000 & 800 & -800 & -4000 \\
\hline 12 & 5 & Vertical & -143 & -238 & 1800 & 1400 & 1200 & 1200 \\
\hline 13 & 20 & Horizontal & -6692 & $-11,154$ & 0 & 6500 & 6500 & 6500 \\
\hline 14 & 10 & Horizontal & -3945 & 6,575 & 0 & 6500 & 6500 & 6500 \\
\hline 15 & 10 & Horizontal & -1740 & $-2,900$ & 0 & -6500 & -6500 & -6500 \\
\hline 16 & 10 & Horizontal & 2400 & 4,000 & 0 & -6500 & -6500 & -6500 \\
\hline 17 & 5 & Vertical & 1901 & 3,168 & 3500 & 2800 & 2800 & 4000 \\
\hline 18 & 5 & Vertical & -2770 & $-4,616$ & 3500 & 4800 & 4800 & 4000 \\
\hline 19 & 5 & Vertical & 2640 & 4,400 & 2800 & 2800 & 2800 & 4000 \\
\hline 20 & 5 & Vertical & 814 & 1,356 & 1800 & 1400 & 1200 & 1200 \\
\hline
\end{tabular}

a Load number 550 was a $550^{\circ} \mathrm{F}$ heating check.

bpressure load maintained at $0.75-1 b / 1 n^{2}$.

cPositive values indicate tension, negative values indicate compression. 
Table 1 Concluded.

(c) $T=1000^{\circ} \mathrm{F}$

\begin{tabular}{|c|c|c|c|c|c|c|c|c|}
\hline \multirow{3}{*}{$\begin{array}{c}\text { Jack } \\
\text { number }\end{array}$} & \multirow{3}{*}{$\begin{array}{l}\text { Load cell } \\
\text { size, lb }\end{array}$} & \multirow{3}{*}{$\begin{array}{c}\text { Jack } \\
\text { position }\end{array}$} & \multicolumn{6}{|c|}{ Load condition identification number } \\
\hline & & & $9.3 b$ & $9.5^{b}$ & $8.1^{\mathrm{C}}$ & $8.2 c$ & $8.3 C$ & $8.4 \mathrm{C}$ \\
\hline & & & \multicolumn{6}{|c|}{ Maximum load, d lb } \\
\hline 1 & $5 \times 10^{3}$ & Vertical & 2521 & 4,201 & 3500 & 2800 & 1200 & -4000 \\
\hline 2 & 10 & Vertical & 1304 & 2,173 & 6000 & 2800 & 2000 & 2400 \\
\hline 3 & 10 & Vertical & 935 & 1,559 & 6000 & 2800 & 2000 & 2400 \\
\hline 4 & 5 & Vertical & 1294 & 2,157 & 3500 & 2800 & -2800 & -4000 \\
\hline 5 & 5 & Horizontal & 1650 & 2,750 & 0 & -5000 & -5000 & -5000 \\
\hline 6 & 10 & Horizontal & 4260 & 7,100 & 0 & -6500 & -6500 & -6500 \\
\hline 7 & 10 & Horizontal & -4030 & $-6,716$ & 0 & 6500 & 6500 & 6500 \\
\hline 8 & 10 & Horizontal & -1232 & $-2,054$ & 0 & 6500 & 6500 & 6500 \\
\hline 9 & 10 & Horizontal & -3840 & $-6,350$ & 0 & 6000 & 6000 & 6000 \\
\hline 10 & 10 & Horizontal & 737 & 1,229 & 0 & 6000 & 6000 & 6000 \\
\hline 11 & 10 & Vertical & 3398 & 5,663 & 3000 & 800 & -800 & -4000 \\
\hline 12 & 5 & Vertical & -143 & -238 & 1800 & 1400 & 1200 & 1200 \\
\hline 13 & 20 & Horizontal & -6692 & $-11,154$ & 0 & 6500 & 6500 & 6500 \\
\hline 14 & 10 & Horizontal & -3945 & $-6,575$ & 0 & 6500 & 6500 & 6500 \\
\hline 15 & 10 & Horizonta1 & -1740 & $-2,900$ & 0 & -6500 & -6500 & -6500 \\
\hline 16 & 10 & Horizontal & 2400 & 4,000 & 0 & -6500 & -6500 & -6500 \\
\hline 17 & 5 & Vertical & 1901 & 3,168 & 3500 & 2800 & 2800 & 4000 \\
\hline 18 & 5 & Vertical & -2770 & $-4,616$ & 3500 & 4800 & 4800 & 4000 \\
\hline 19 & 5 & Vertical & 2640 & 4,400 & 2800 & 2800 & 2800 & 4000 \\
\hline 20 & 5 & Vertical & 814 & 1,356 & 1800 & 1400 & 1200 & 1200 \\
\hline
\end{tabular}

a Load number 9.1 was a $1000^{\circ} \mathrm{F}$ (Mach 8 ) heating check.

bpressure load maintained at $0.75-1 b / 1 n^{2}$.

CTests conducted at pressure loads of 0 and $0.75 \mathrm{lb} / \mathrm{nn}^{2}$.

dpositive values indicate tension, negative values indicate compression. 
Table 2 Test identification numbers and corresponding load conditions

\begin{tabular}{|c|c|c|c|}
\hline $\begin{array}{c}\text { Test } \\
\text { number }\end{array}$ & $\begin{array}{l}\text { Load } \\
\text { condition }\end{array}$ & $\begin{array}{c}\text { Pressure, } \\
1 \mathrm{~b} / \mathrm{nn}^{2}\end{array}$ & $\begin{array}{c}\text { Temperature, } \\
\mathrm{F}^{\circ}\end{array}$ \\
\hline $\begin{array}{l}4.1 .4 \\
4.2 .6 \\
4.3 .3 \\
4.4 .6 \\
4.2 .7 \\
4.3 .4 \\
4.4 .7 \\
7.2 .4 \\
7.3 .5 \\
7.4 .4\end{array}$ & $\begin{array}{l}4.1 \\
4.2 \\
4.3 \\
4.4 \\
4.2 \\
4.3 \\
4.4 \\
4.2 \\
4.3 \\
4.4\end{array}$ & $\begin{array}{l}0.75 \\
0.75 \\
0.75 \\
0.75 \\
0 \\
0 \\
0 \\
0.75 \\
0.75 \\
0.75\end{array}$ & $\begin{array}{r}70 \\
70 \\
70 \\
70 \\
70 \\
70 \\
70 \\
550 \\
550 \\
550\end{array}$ \\
\hline $\begin{array}{l}7.1 .8 \\
6.8 .3 \\
8.2 .2 \\
8.2 .2 \\
8.3 .2 \\
8.3 .2 \\
8.3 .5 \\
8.3 .5 \\
8.4 .6 \\
8.4 .6\end{array}$ & $\begin{array}{l}7.1^{\mathrm{a}} \\
3.8 \\
4.2 \\
4.2 \\
4.3 \\
4.3 \\
4.3 \\
4.3 \\
4.4 \\
4.4\end{array}$ & $\begin{array}{l}0.75 \\
0.75 \\
0 \\
0.75 \\
0 \\
0.75 \\
0 \\
0.75 \\
0 \\
0.75\end{array}$ & $\begin{array}{r}550 \\
550 \\
1000 \\
1000 \\
1000 \\
1000 \\
1000 \\
1000 \\
1000 \\
1000\end{array}$ \\
\hline 8.1 .3 & $8.1^{\mathrm{a}}$ & 0 & 1000 \\
\hline $\begin{array}{c}8.1 .3 \\
\text { Single-Panel } \\
\text { Test } 1.1\end{array}$ & $N_{x} \neq 0, N_{x y}^{a}=0$ & $\begin{array}{l}0.75 \\
0\end{array}$ & $\begin{array}{r}1000 \\
70\end{array}$ \\
\hline $\begin{array}{c}\text { Single-Panel } \\
\text { Test } 3.1\end{array}$ & $N_{x} \neq 0, N_{x y}=0$ & 0 & 70 \\
\hline
\end{tabular}

a Equivalent to load condition 4.1 . 


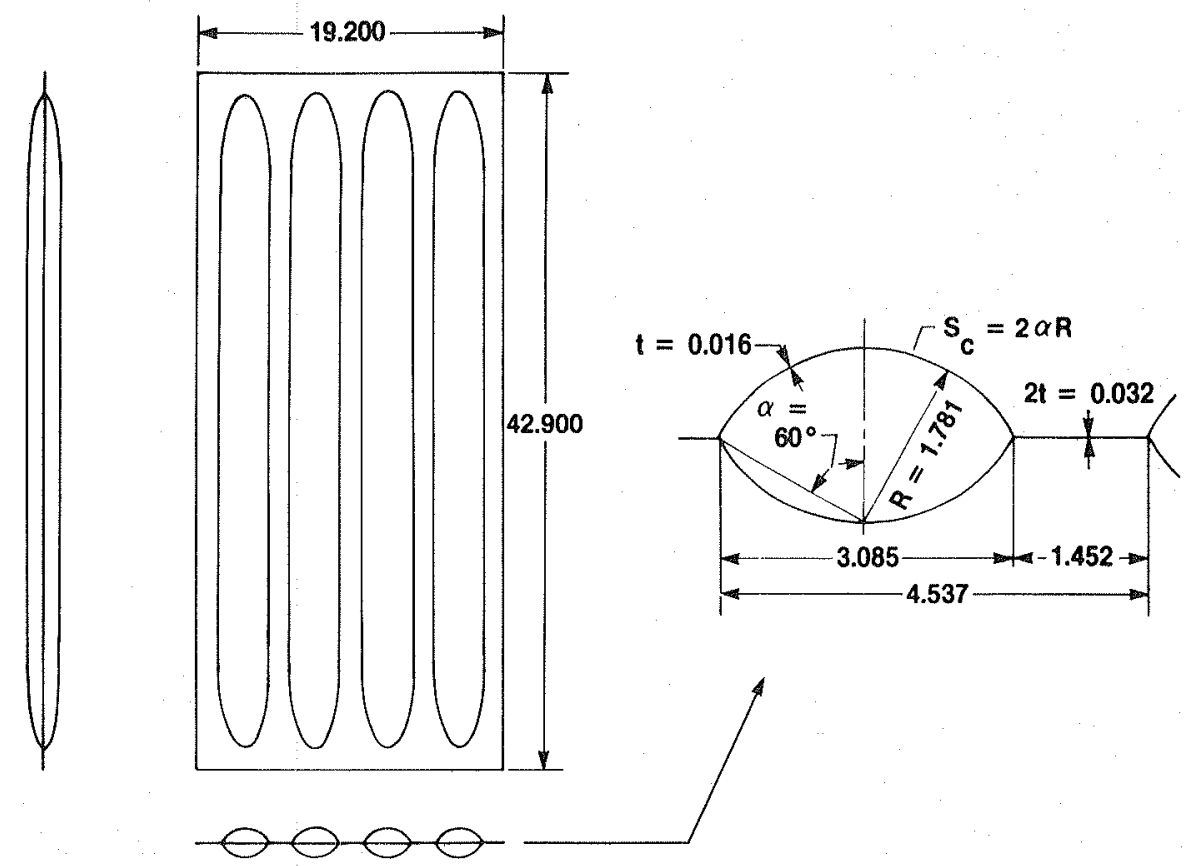

Fig. 1 Geometry of tubular panel (dimensions in inches). panel weight is $13 \mathrm{lb}$.

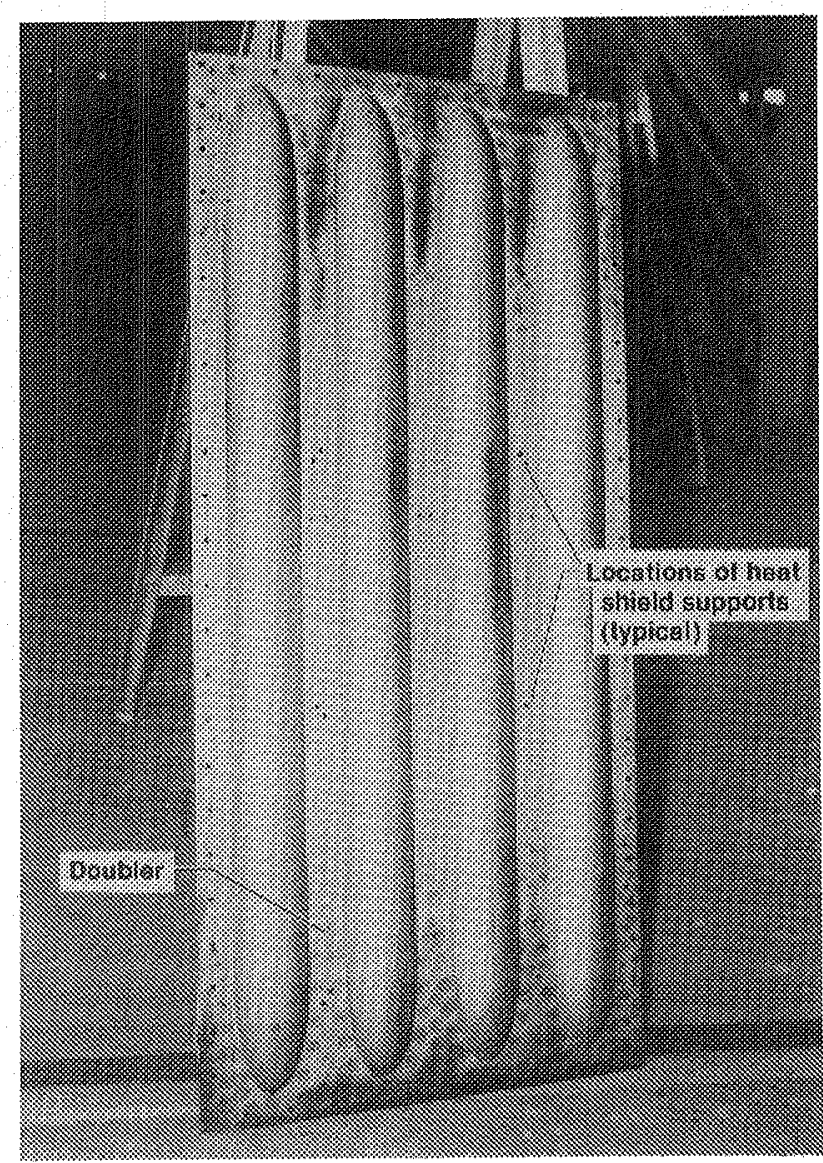

E 29938

Fig. 2 Photograph of René 41 tubular panel with heat shield supports removed. 


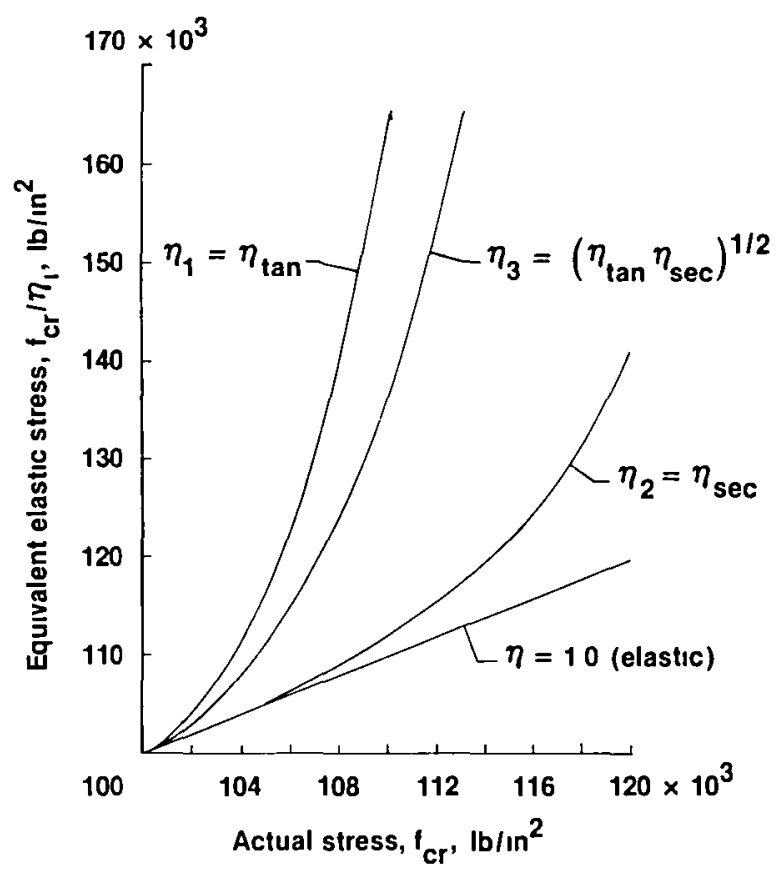

Frg. 3 Plastrcity correction curves for local buckling of René 41 circular arc element, where $T=70^{\circ} \mathrm{F}, E=31.6 \times 10^{6} \mathrm{lb} / 2 \mathrm{n}^{2}$, and $f_{c y}=$ $125 \times 10^{3} \mathrm{zb} / 2 n^{2}$ (Ref. 2, eqs. 12-54 and $12-55$ setting $n=25$ ).

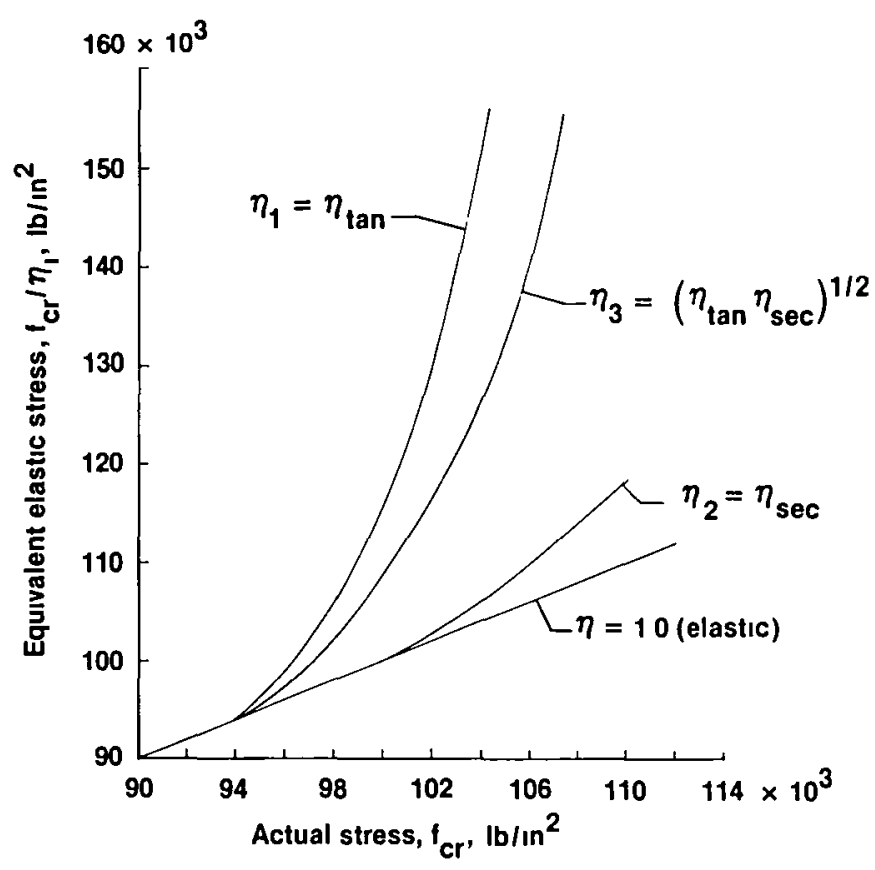

Fig. 4 Plasticrty correction curves for local buckling of René 41 circular arc element, where $T=550^{\circ} \mathrm{F}, E=29.1 \times 10^{6} \mathrm{lb} / \mathrm{Ln}^{2}$, and $f_{c y}=$ $120 \times 10^{3} \mathrm{lb} / \mathrm{Ln}^{2}$ (Ref. 2, eqs. $12-54$ and $12-55$ settrng $n=22.2$ ).

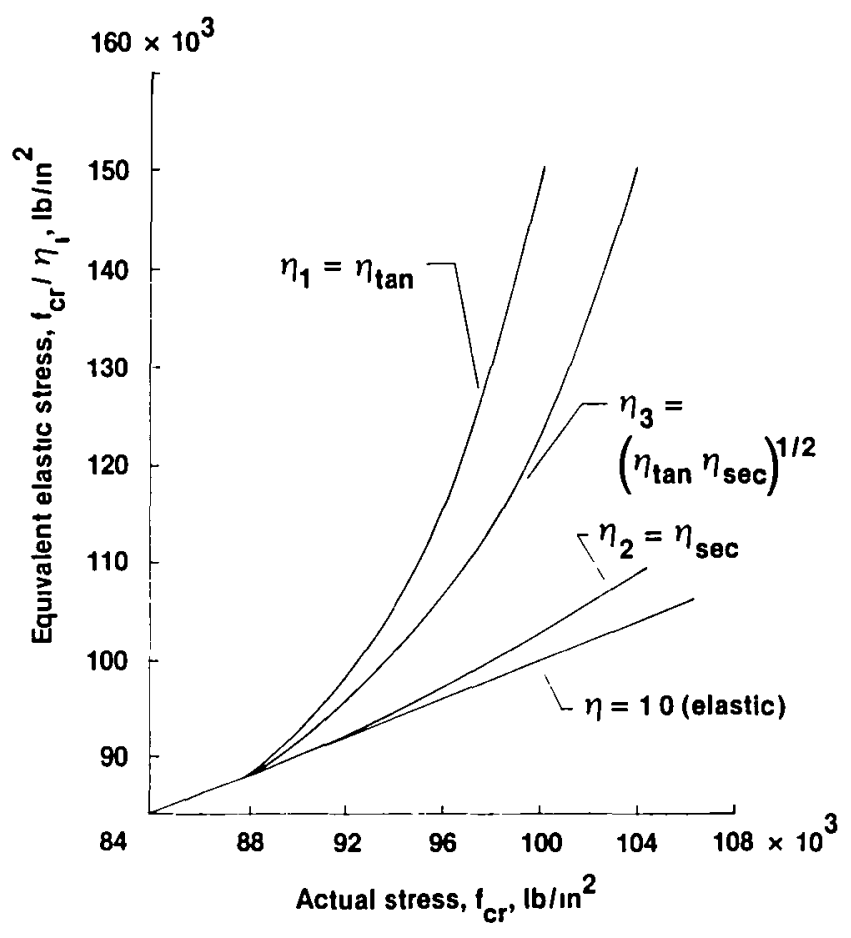

Fig. 5 Plasticrty correction curves for local bucklıng of René 41 circular arc element, where $T=1000^{\circ} \mathrm{F}, E=26.5 \times 10^{6} \mathrm{lb} / 2 \mathrm{n}^{2}, f_{c y}=$

$117 \times 10^{3} \mathrm{zb} / 2 n^{2}$ (Ref. 2, eqs. 12-54 and 12-55 settrng $n=18.5$ ). 


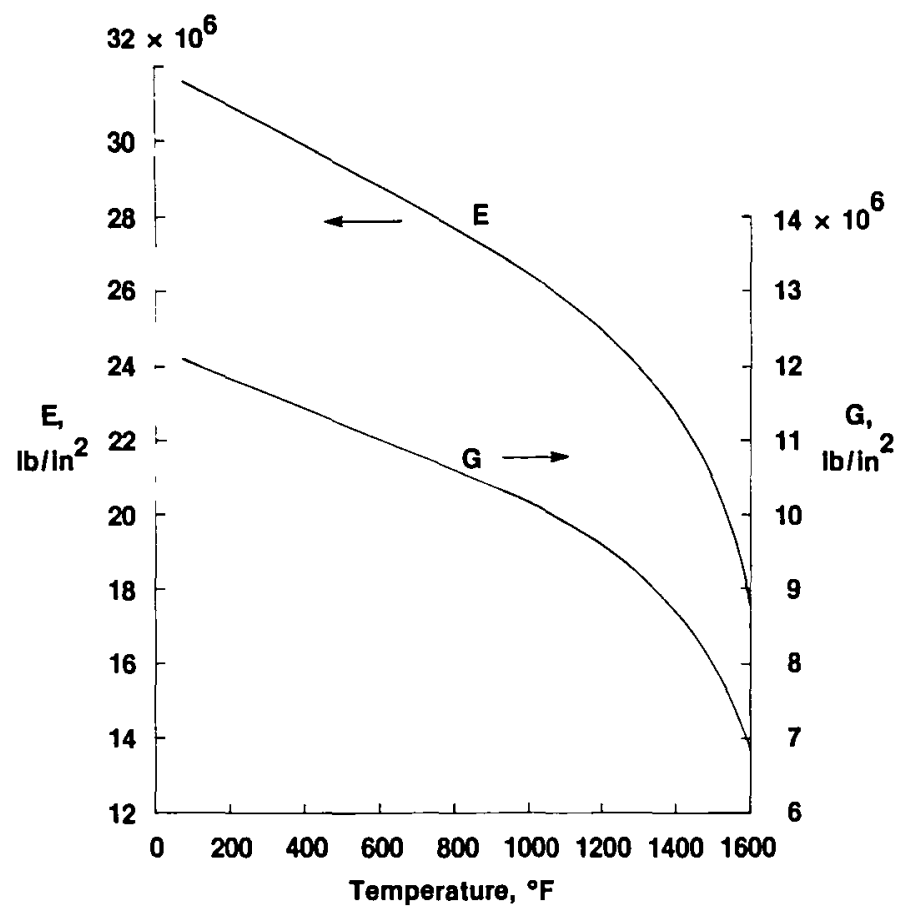

Fig. 6 Modulus of elasticity and modulus of rigidity as functions of temperature for René 41 (from Ref. 12).

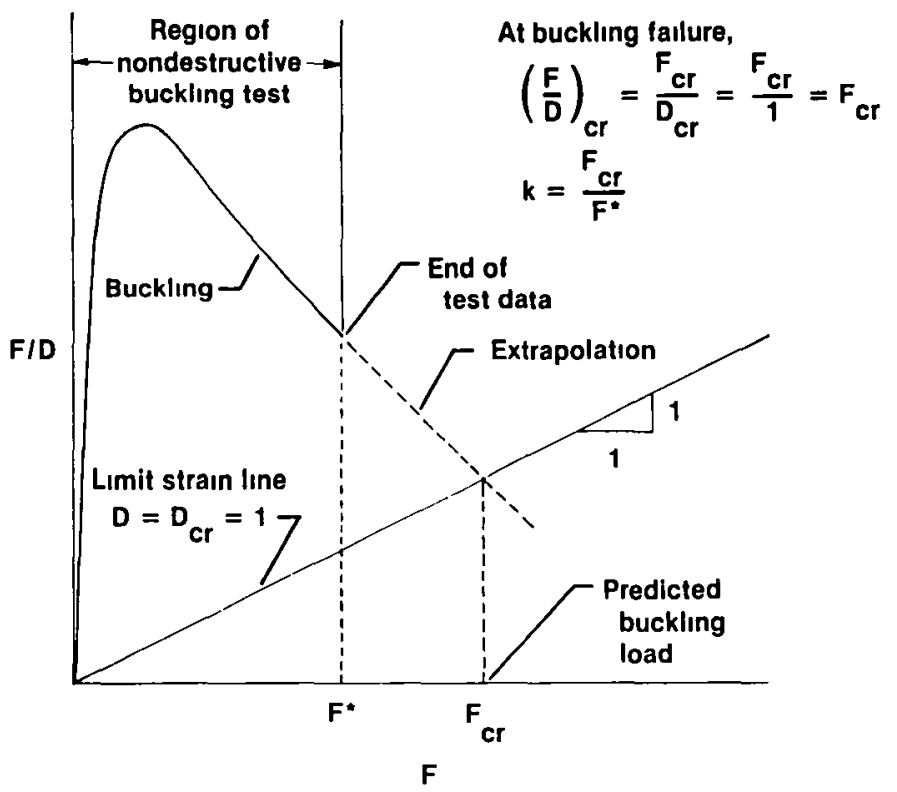

Fig. 7 Force/stiffness plot for local buckling. 


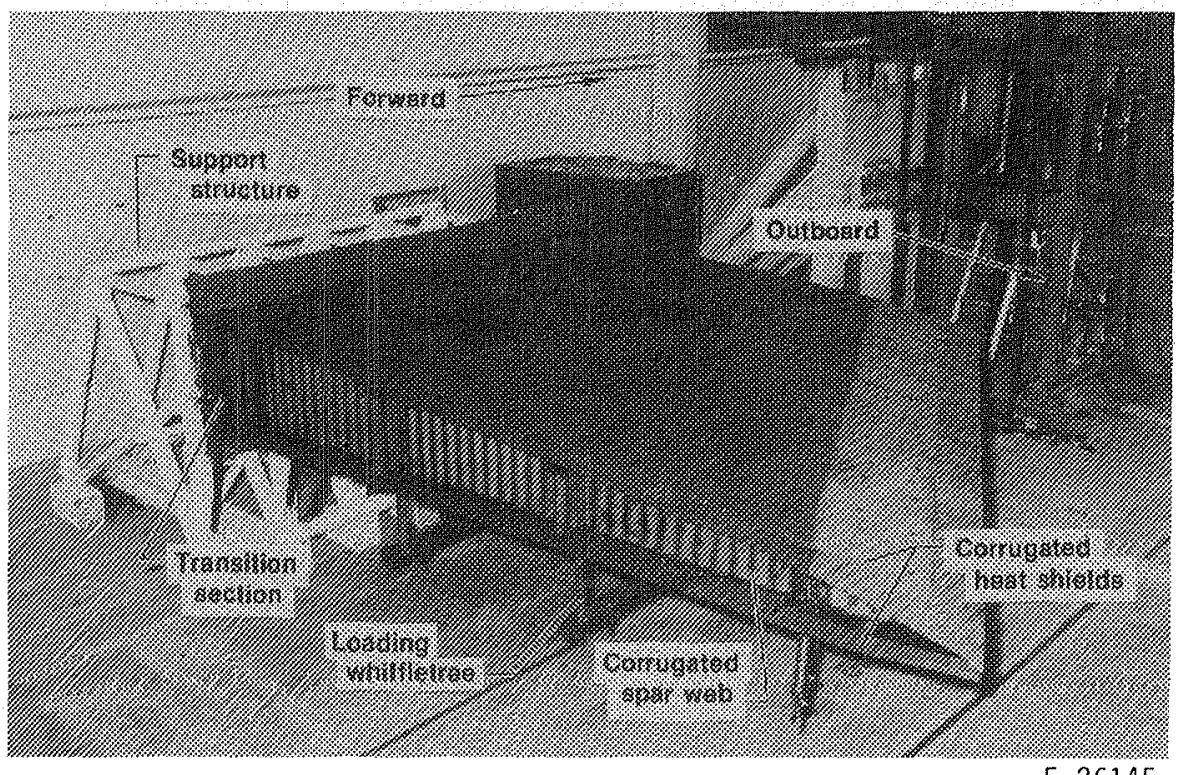

E 26145

Fig. 8 Hypersonic wing test structure (HWTS).

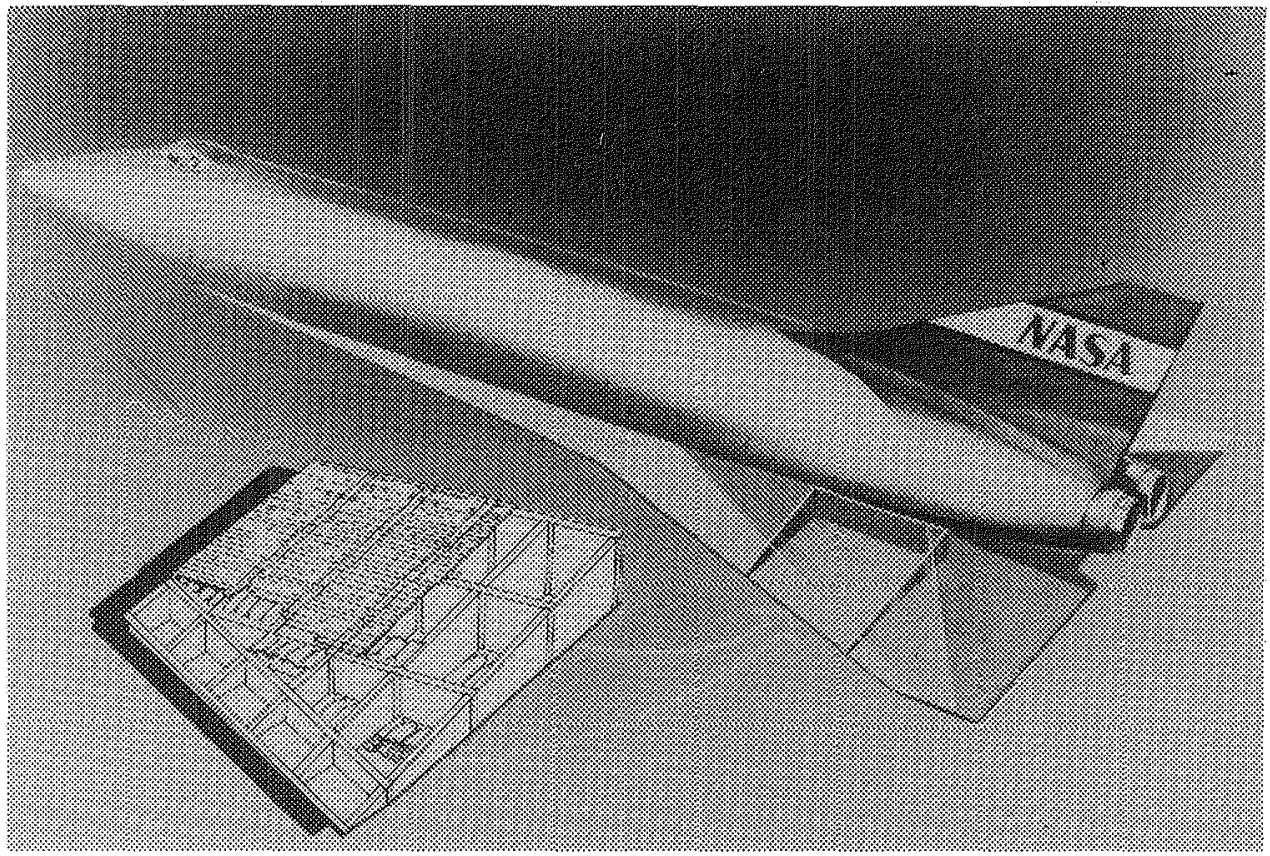

DFRC80-236

Fig. 9 Position of hypersonic wing test structure in proposed HRA. 


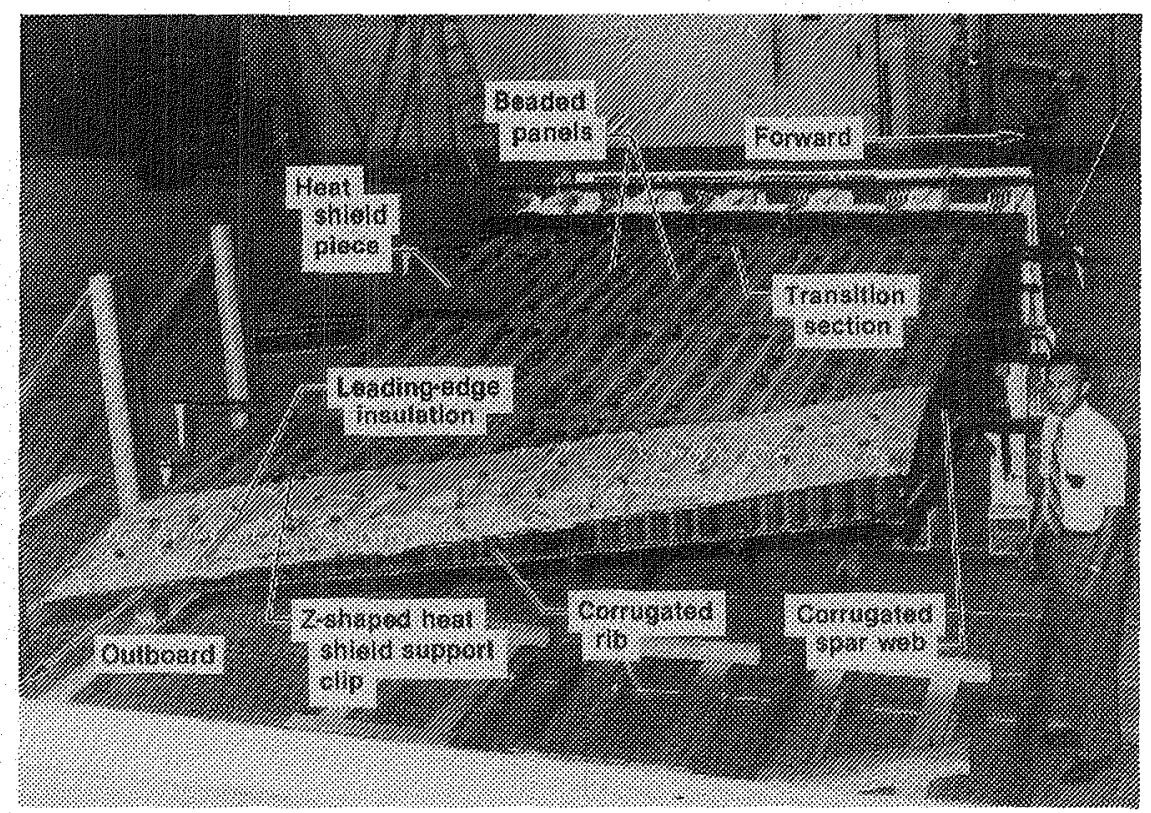

Fig. 10 Hypersonic wing test structure with heat shields removed to show substructure.

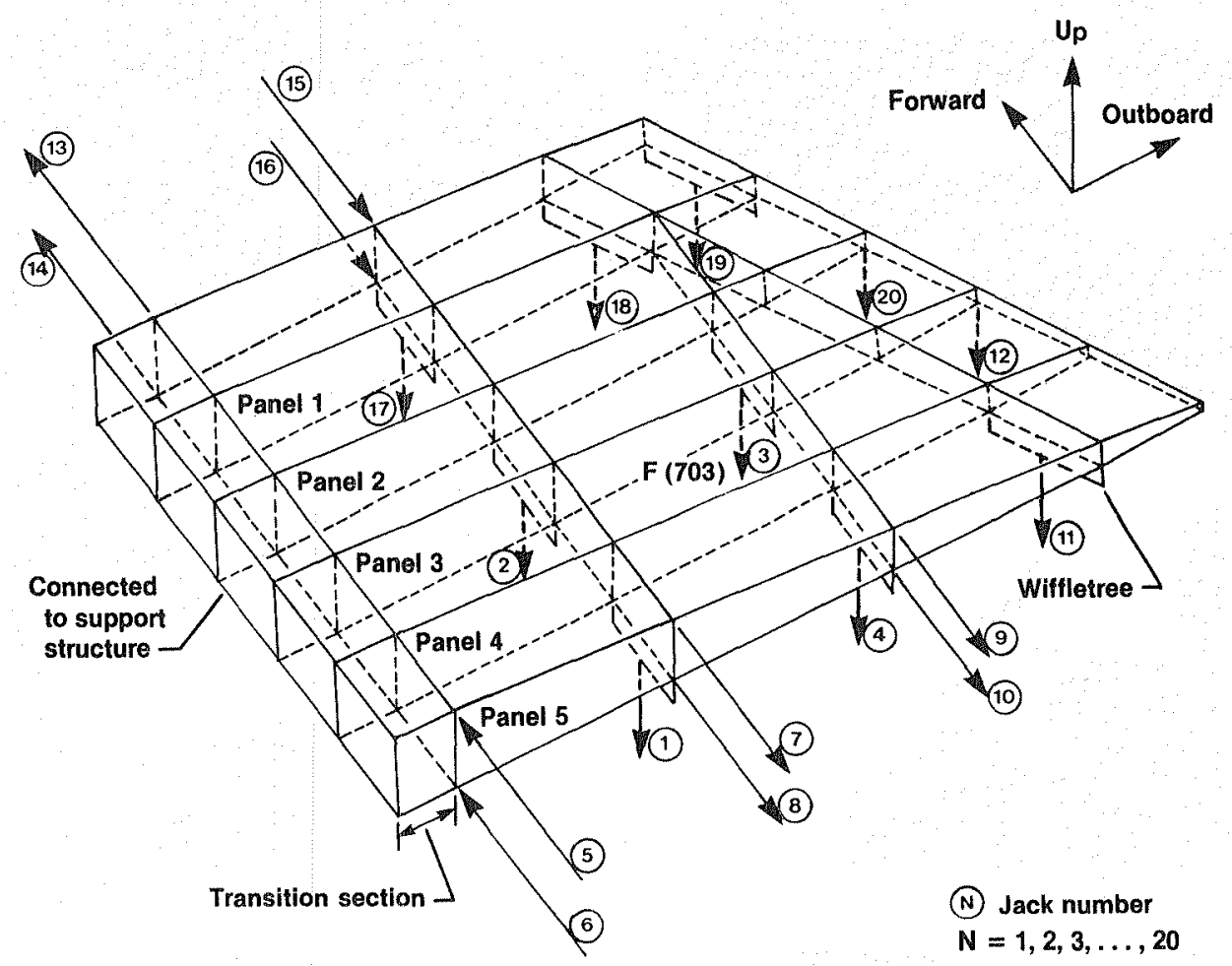

Fig. 11 Applied mechanical load distribution on HWTS and locations of five test tubular panels. 


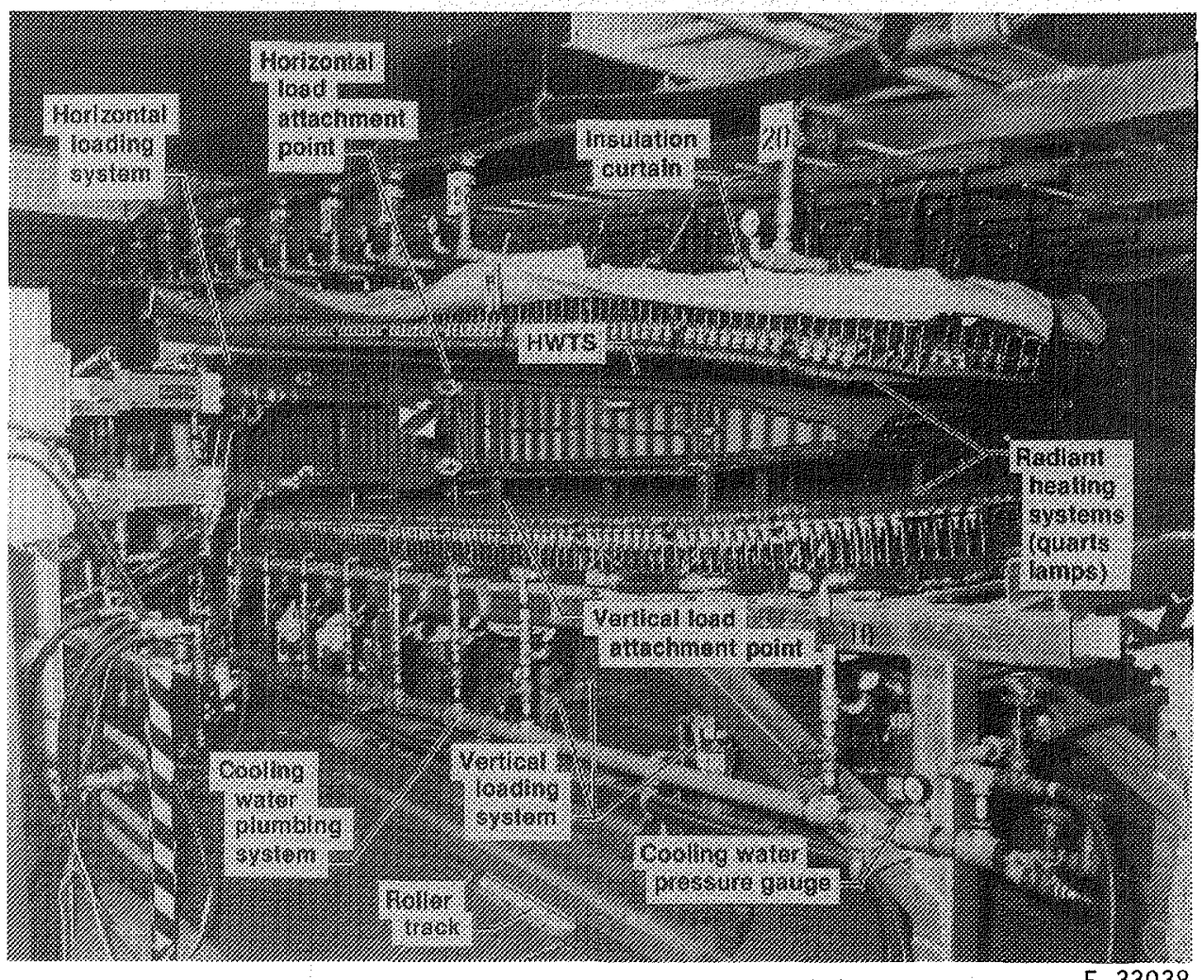

E 33038

Fig. 12 HWTS combined mechanical and thermal loading test setup. 


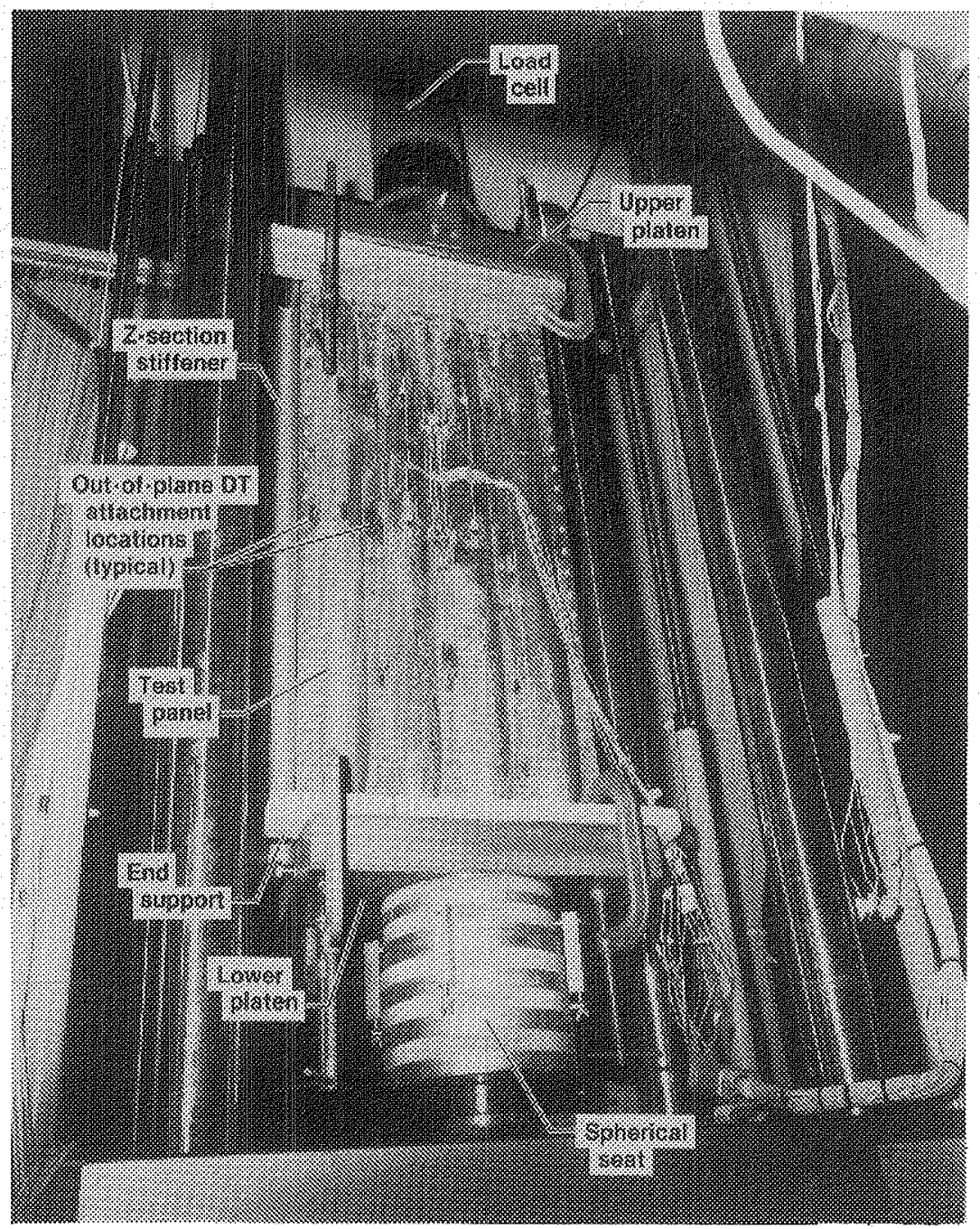

E $40425-2$

Fig. 13 Tubular panel test assembly installed in the testing machine for axial compression buckling test. 
Panel 1

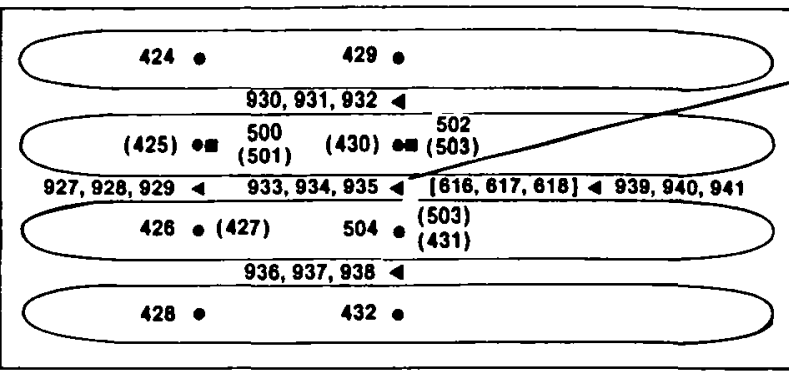

Panel 2
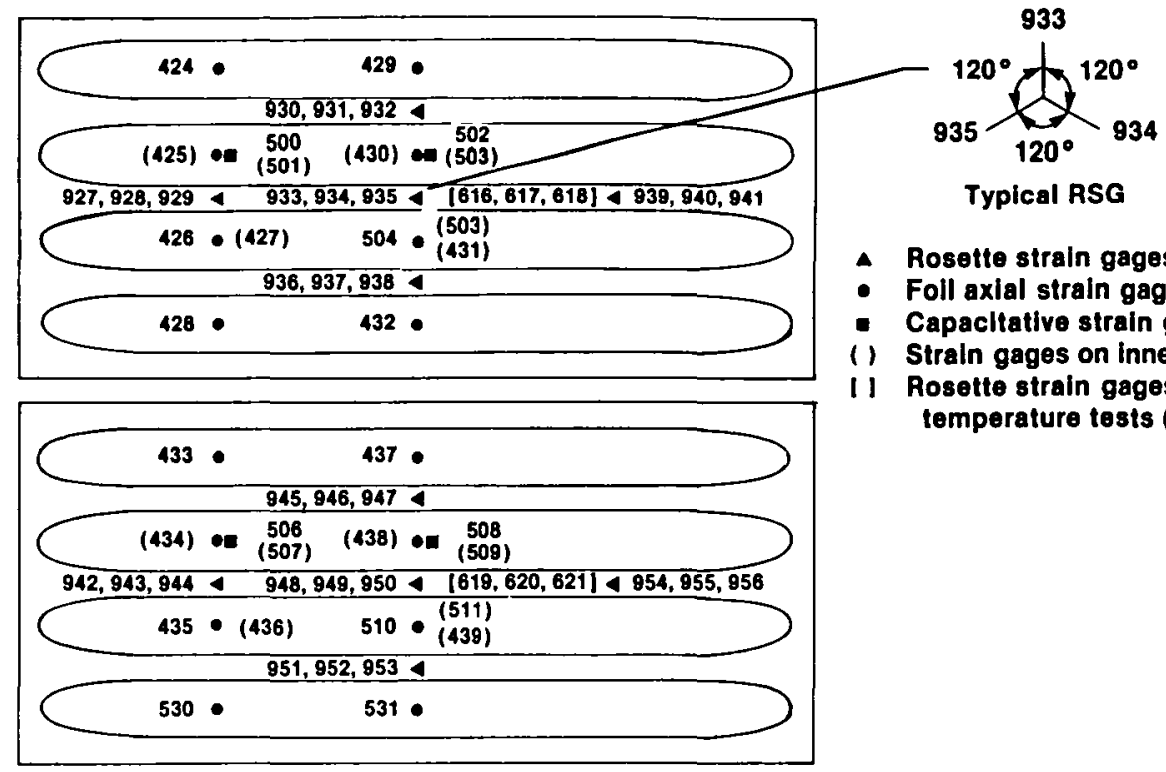

- Rosette strain gages (RSG)

- Foll axial strain gages (ASG)

- Capacltative strain gages (CSG)

(1) Straln gages on inner (upper) surfaces

I] Rosette strain gages used for elevated. temperature tests (panel center)

Panel 3

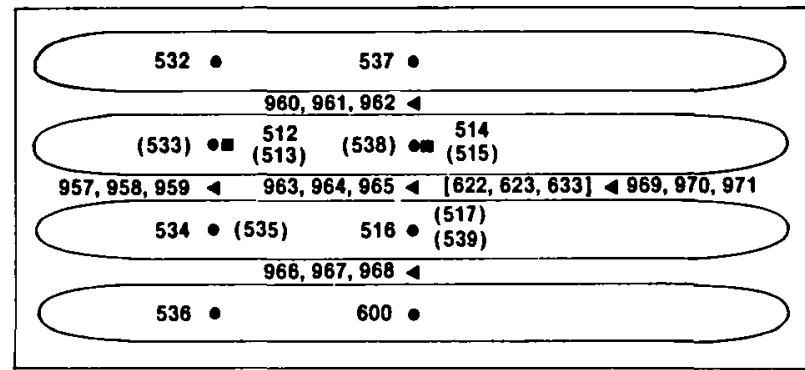

Panel 4

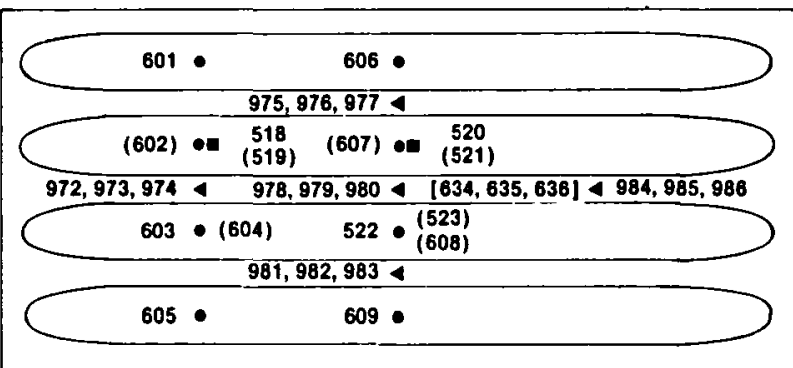

Panel 5
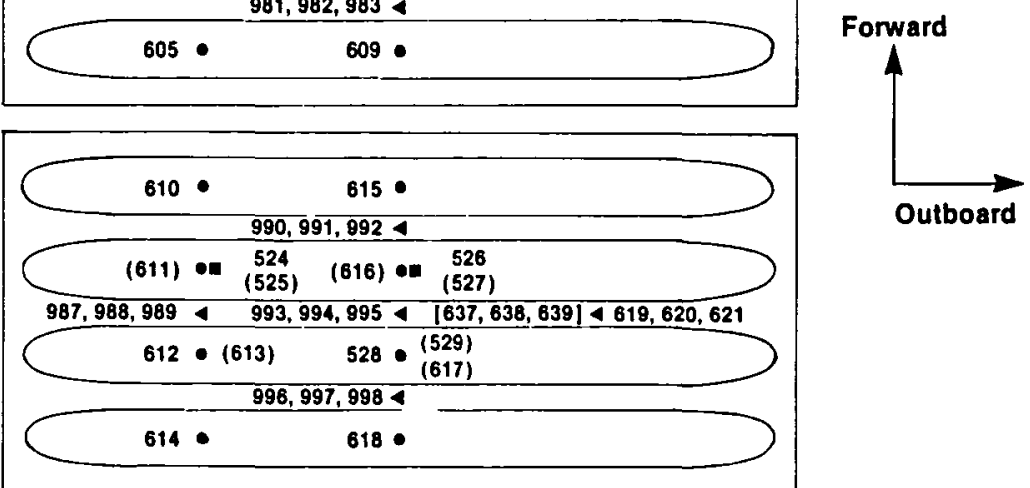

Fig. 14 Locations of strain gages on five tubular test panels (view looking downward). 


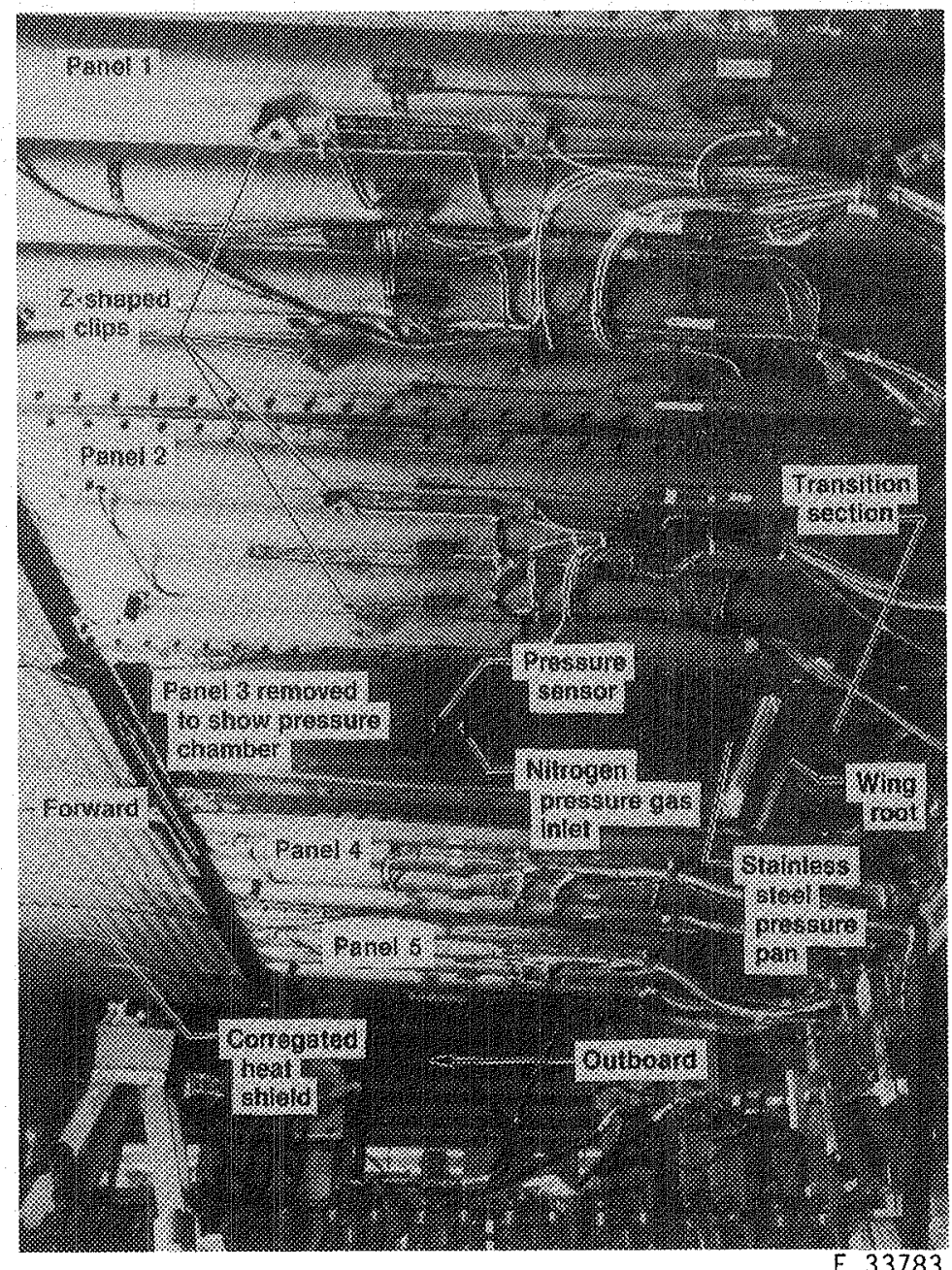

Fig. 15 Four Rene 41 tubular panels attached to the hypersonic wing test structure for buckling tests (view looking up and aft at the lower side of test structure). Panel 3 was removed to show the pressure pan. 

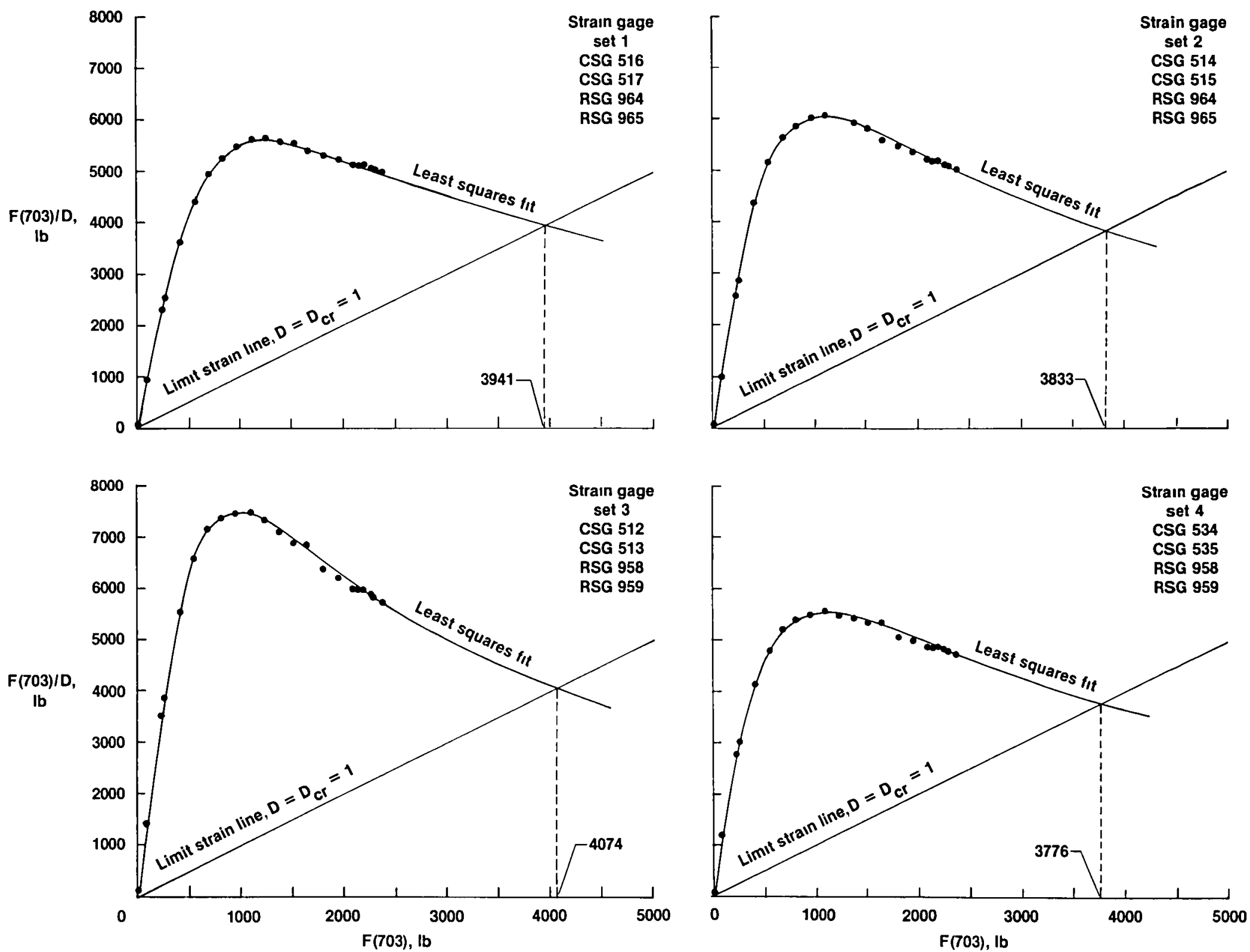

F2g. 16 Force/stıffness plots for panel 3, test $4.4 .6, T=70^{\circ} \mathrm{F}, p=0.75 \mathrm{lb} / \mathrm{in}^{2}$. 

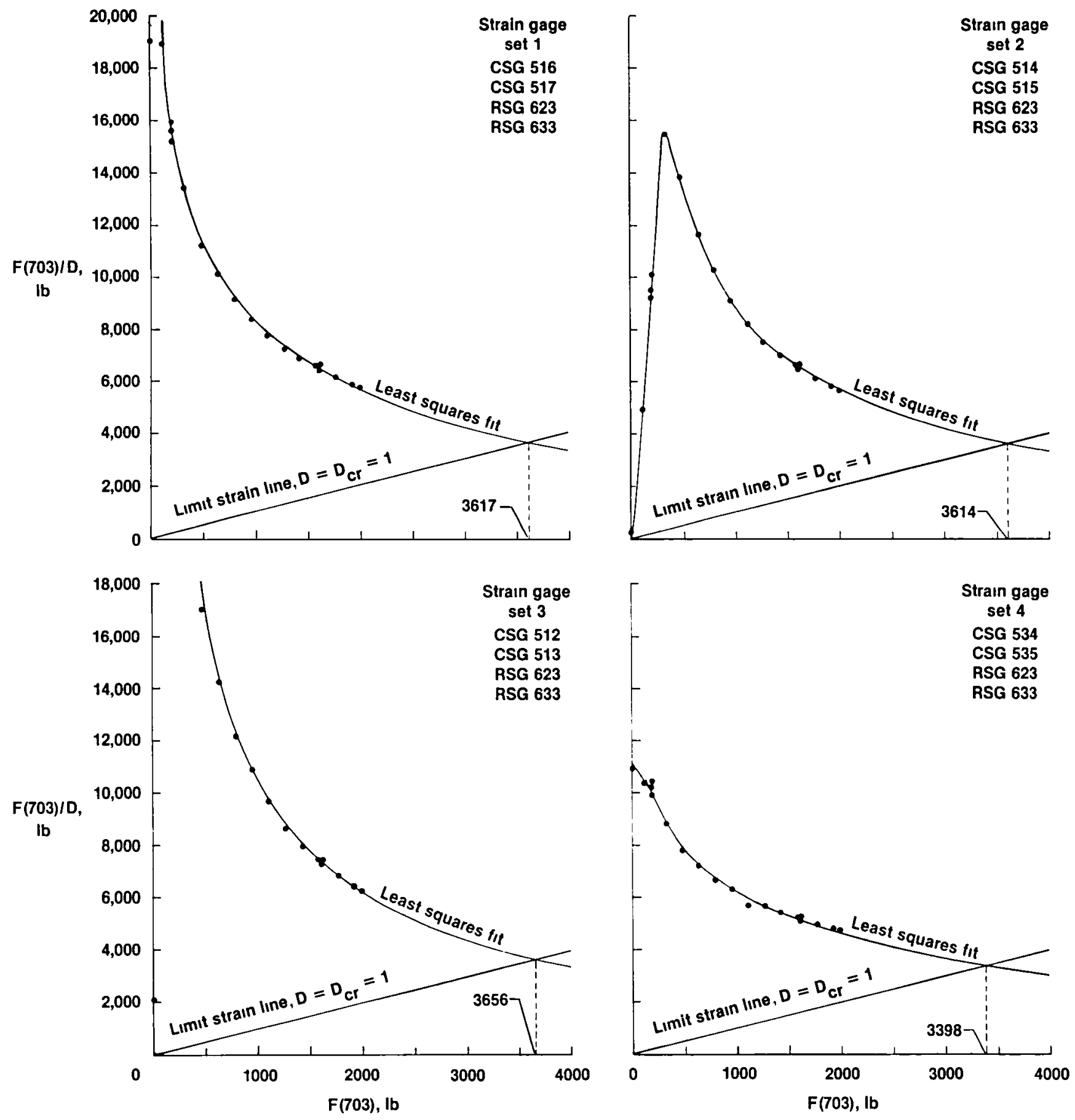

Fig. 17 Force/stiffness plots for panel 3, test $4.3 .4, T=70^{\circ} \mathrm{F}, p=0$. 

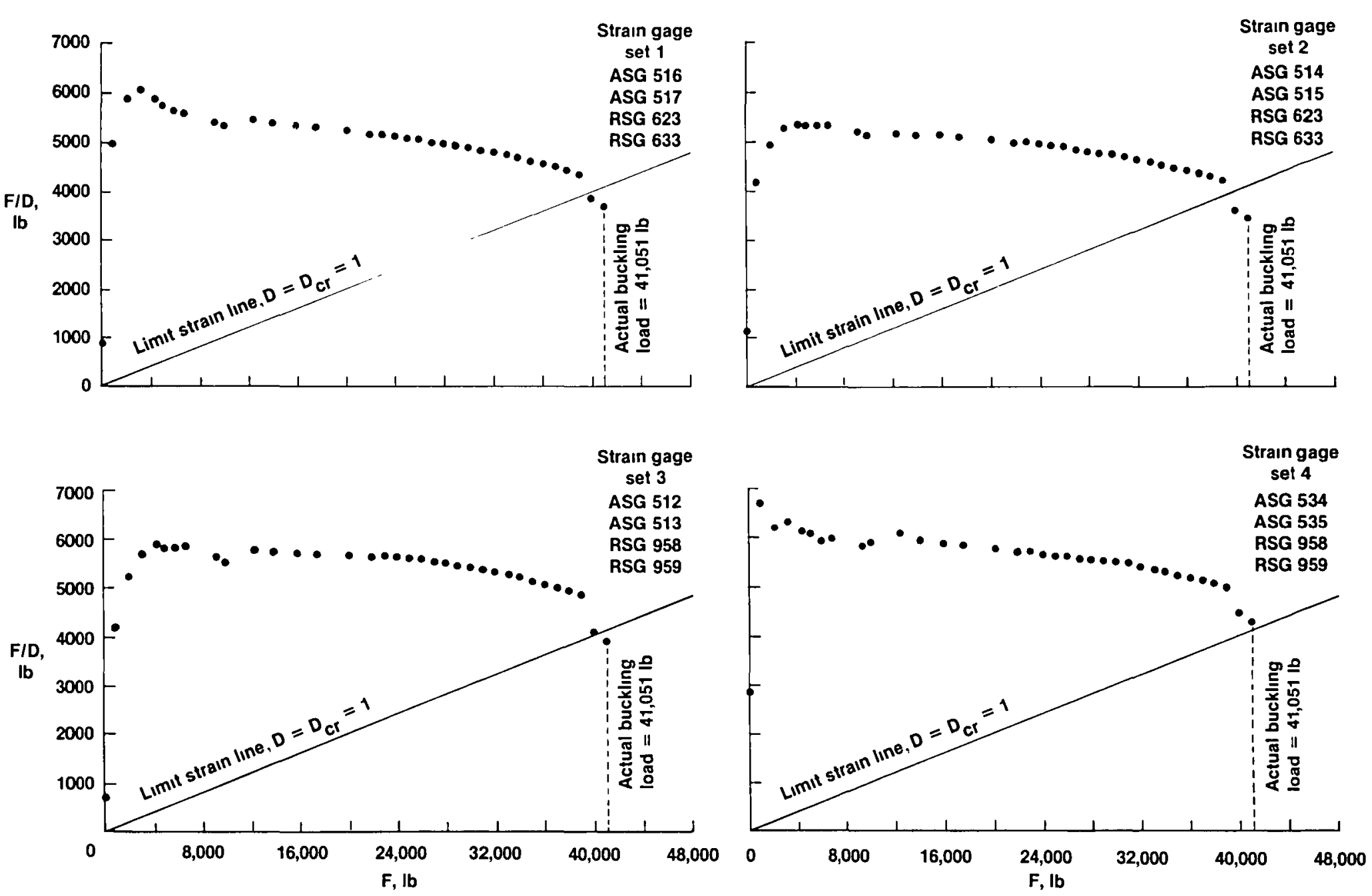

Fig. 18 Force/strffness plots for single-panel compresszon test up to farlure; panel $3, T=70^{\circ} \mathrm{F}, p=0$. 


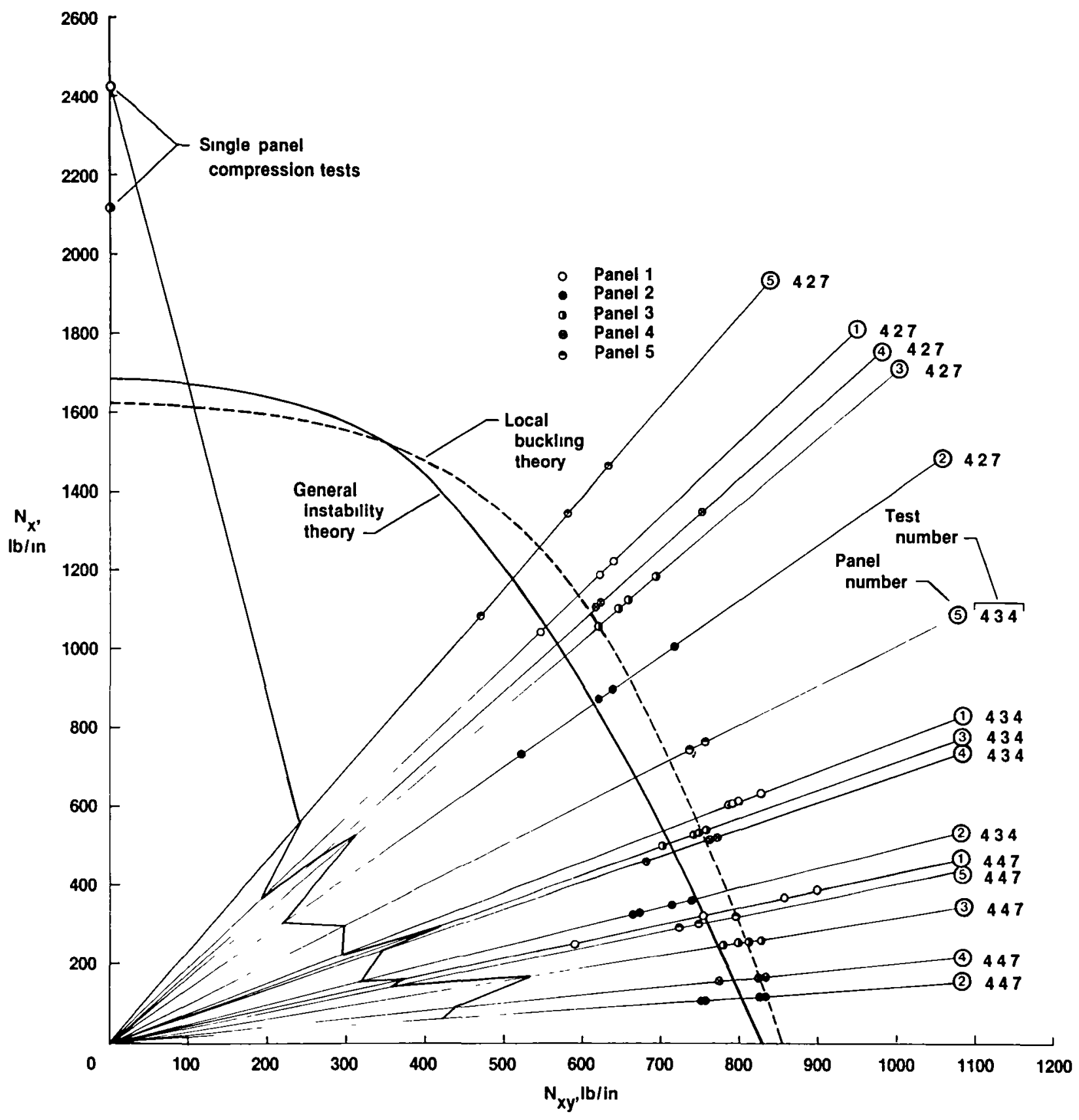

Fig. 19 Buckling interaction plots for René 41 tubular panels $\left(T=70^{\circ} \mathrm{F}, p=0\right)$. 


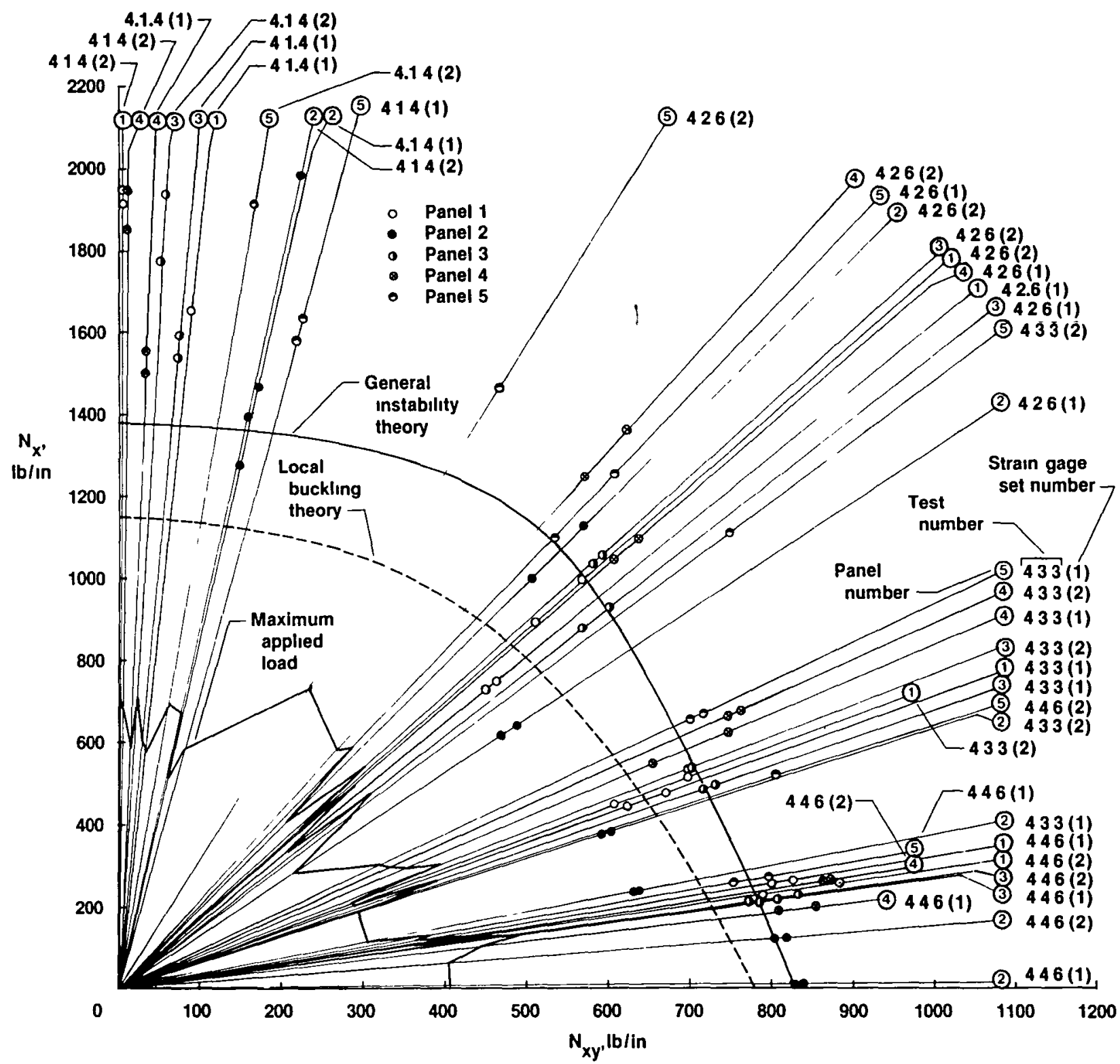

Fig. 20 Buckling interaction plots for René 41 tubular panel $\left(T=70^{\circ} \mathrm{F}, p=0.75\right.$ lb/in $\left.{ }^{2}\right)$. Strain gage sets are defined in Figs. 16 to 18. 


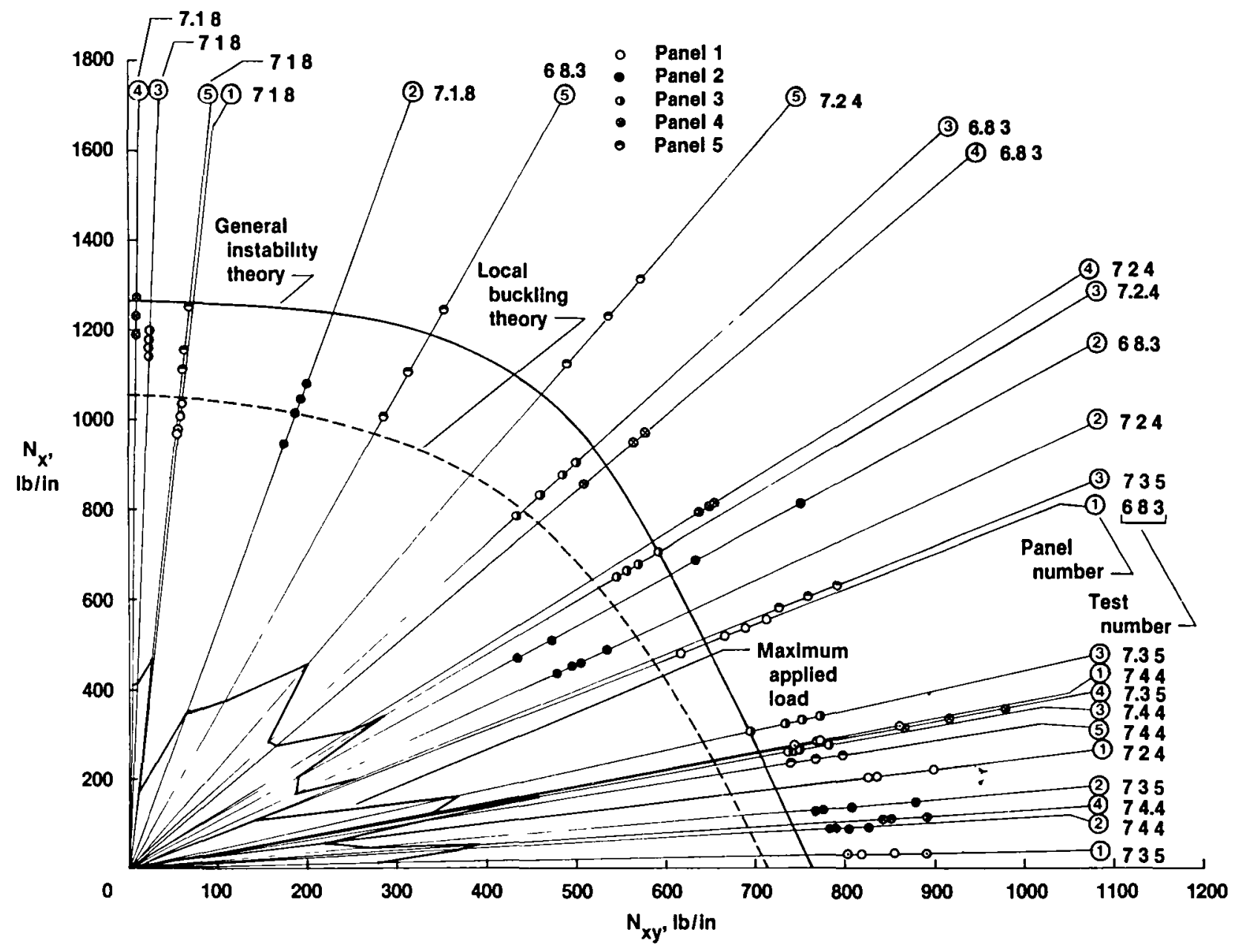

Fig. 21 Buckling interaction plots for René 41 tubular panels $\left(T=550^{\circ} \mathrm{F}, p=0.75 \mathrm{lb} / \mathrm{in}{ }^{2}\right)$. 


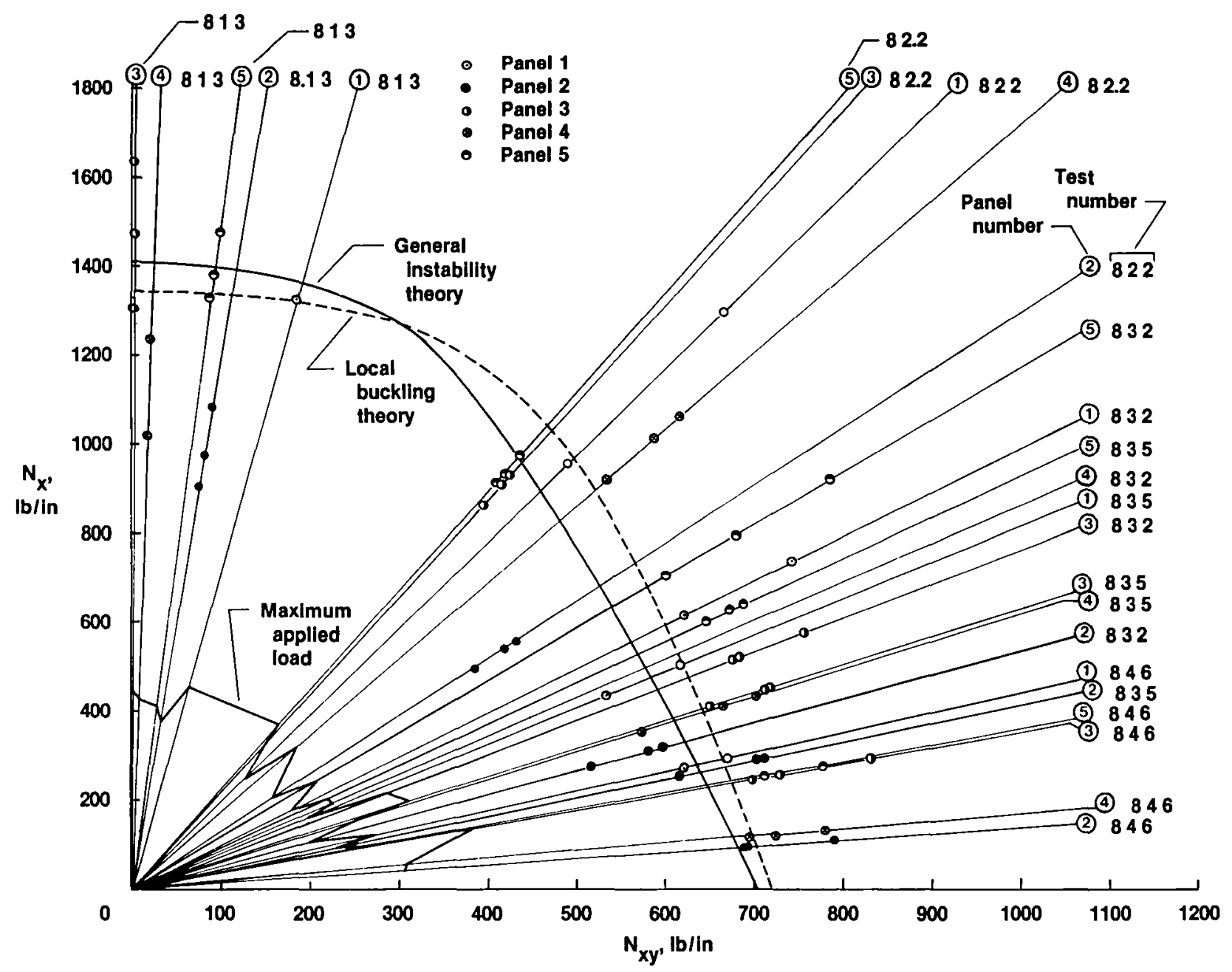

Fıg. 22 Buckling interaction plots for René 41 tubular panels $\left(T=1000^{\circ} \mathrm{F}, p=0\right)$. 


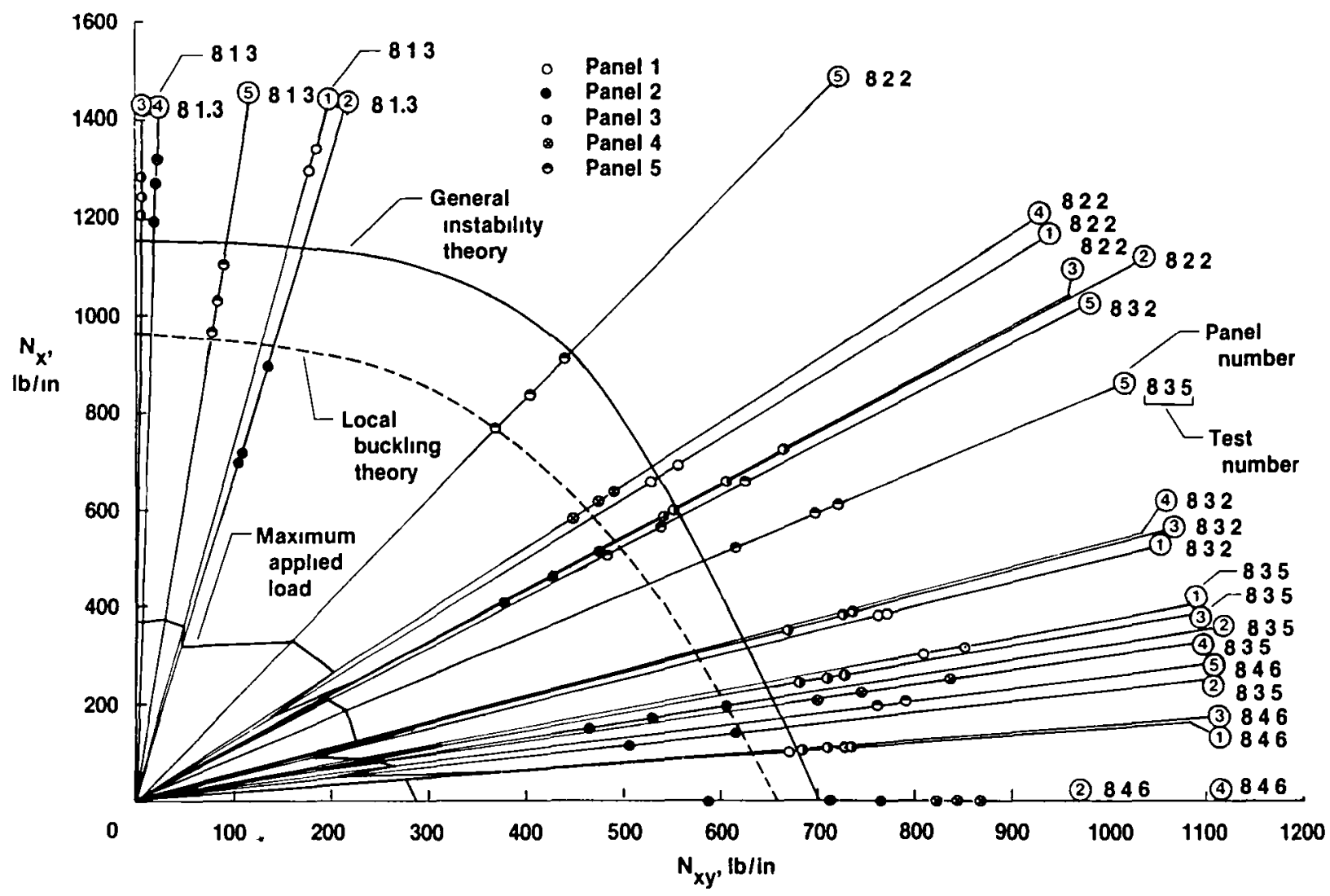

Fig. 23 Buckling interaction plots for René 41 tubular panels $\left(T=1000^{\circ} \mathrm{F}, p=0.75 \mathrm{lb} / \mathrm{in} \mathrm{n}^{2}\right)$. 


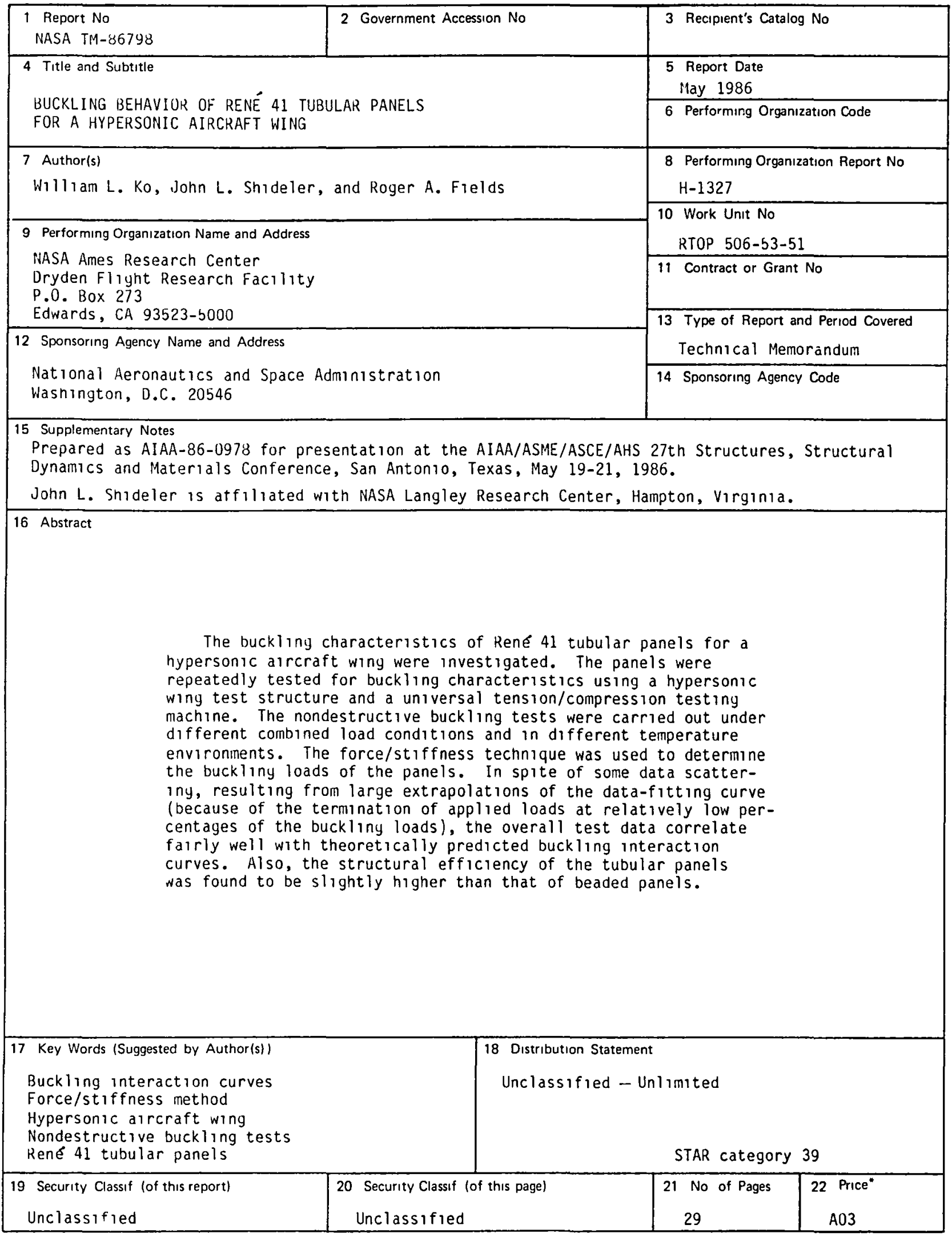

*For sale by the Natronal Technucal Information Service, Springfield, Virginza 22161. 


\section{End of Document}

